Article

\title{
Insights into the Surface Transformation and Electrochemical Dissolution Process of Bornite in Bioleaching
}

\author{
Hongbo Zhao ${ }^{1,2,3}$, Xiaotao Huang ${ }^{1,2}$, Minghao Hu ${ }^{1,2}$, Chenyang Zhang ${ }^{1,2} \mathbb{D}^{\mathbb{D}}$, Yisheng Zhang ${ }^{1,2}$, \\ Jun Wang ${ }^{1,2, *}$, Wenqing Qin ${ }^{1,2}$ and Guanzhou Qiu ${ }^{1,2}$ \\ 1 School of Minerals Processing \& Bioengineering, Central South University, Changsha 410083, China; \\ zhbalexander@csu.edu.cn (H.Z.); huangxiaotao810@163.com (X.H.); minghaohu@outlook.com (M.H.); \\ zhangchenyang@csu.edu.cn (C.Z.); zys666@csu.edu.cn (Y.Z.); qinwenqingcsu@126.com (W.Q.); \\ qiuguanzhoucsu@126.com (G.Q.) \\ 2 Key Lab of Biohydrometallurgy of Ministry of Education, Changsha 410083, China \\ 3 State Key Laboratory of Complex Nonferrous Metal Resources Clean Utilization, Kunming 650093, China \\ * Correspondence: wjwq2000@126.com; Tel.: +86-0731-8887-6557
}

Received: 23 March 2018; Accepted: 20 April 2018; Published: 23 April 2018

check for updates

\begin{abstract}
In this work, density functional theory (DFT) calculations, X-ray photoelectron spectroscopy (XPS) and electrochemistry analysis were combined to analyze the electrochemical dissolution process of bornite during bioleaching. DFT calculations showed that bornite was a conductor with metallic conductivity. The formula of bornite may be $\left(\mathrm{Cu}^{+}\right)_{5} \mathrm{Fe}^{3+}\left(\mathrm{S}^{2-}\right)_{4}$ and the surface reconstruction of (111)-S surface was discussed. Electrochemistry and XPS analysis showed that bornite tended to be directly oxidized with high conductivity when the potential was higher than $0.3 \mathrm{~V}$ vs. $\mathrm{Ag} / \mathrm{AgCl}$. Elemental sulfur $\left(\mathrm{S}^{0}\right), \mathrm{FeOOH}$ and $\mathrm{CuS}$ were the main intermediate species on the bornite surface during the oxidation process. The production of $\mathrm{S}^{0}$ and $\mathrm{FeOOH}$ on bornite surface can be significantly accelerated with increased redox potential, but no insoluble sulfate $\left(\mathrm{SO}_{4}{ }^{2-}\right)$ formed on bornite surface in $0.3-0.65 \mathrm{~V}$ vs. $\mathrm{Ag} / \mathrm{AgCl}$. The oxidative dissolution of bornite was significantly accelerated with increasing redox potential, which was one important reason why mixed culture was more effective than single strains of $A$. caldus and L. ferriphilum in bornite bioleaching. The insoluble $\mathrm{SO}_{4}{ }^{2-}$ was formed mainly through the chemical reactions in solution and then covered the bornite surface in bioleaching. Based on the obtained results, a model for interpreting the dissolution process of bornite in bioleaching was proposed.
\end{abstract}

Keywords: bornite; bioleaching; surface transformation; dissolution process; moderately thermophilic microorganisms

\section{Introduction}

Bornite $\left(\mathrm{Cu}_{5} \mathrm{FeS}_{4}\right)$ is a kind of copper resource that is relatively widespread on Earth. Bio-hydrometallurgy (bioleaching) is considered an economically promising technology for clean extraction of sulfide minerals such as chalcopyrite $\left(\mathrm{CuFeS}_{2}\right)$, pyrite $\left(\mathrm{FeS}_{2}\right)$ and chalcocite $\left(\mathrm{Cu}_{2} \mathrm{~S}\right)$ [1]. Hence, bioleaching of bornite is an important research topic and the dissolution mechanisms of bornite during bioleaching should be firstly studied to enhance its bioleaching efficiency. Bornite is considered as an intermediate species in chalcopyrite bioleaching, and chalcopyrite was also reported as the intermediate species during bornite bioleaching [2-5]. Therefore, the study of dissolution mechanisms of bornite during bioleaching is also essential for interpreting the dissolution mechanisms of chalcopyrite bioleaching. Some publications have reported that bornite has non-ignorable effects on chalcopyrite dissolution [6-8]. The dissolution of sulfides during bioleaching sometimes can be 
regarded as a reverse biomineralization process. Therefore, the research on the surface transformation and dissolution process of bornite in the presence of microorganisms can not only help improve the bioleaching kinetics of bornite and chalcopyrite, but also enhance the geberal understanding of the biomineralization of $\mathrm{Cu}$-sulfides and their geo-biological-chemical circulation on Earth.

Some studies on chemical leaching of bornite have been reported. Price et al. [9] analyzed the dissolution process of bornite in sulfuric acid by combining anodic constant current treatments, solution analysis, electron probe microanalysis and $\mathrm{X}$-ray diffraction. They found that $\mathrm{Cu}_{2.5} \mathrm{FeS}_{4}$ was an intermediate species and the reaction was controlled by the solid state diffusion at $50{ }^{\circ} \mathrm{C}$. Price and Chilton [10] also proposed that the optimum conditions for electroleaching of bornite included high temperature, low current density and the presence of chloride ions. Pesic et al. [5] studied the dissolution of bornite in sulfuric acid using oxygen as an oxidant, and they found that covellite (CuS) and $\mathrm{Cu}_{3} \mathrm{FeS}_{4}$ were the main intermediate species. In addition, the copper dissolution rate was controlled by the iron dissolution rate, and the initial preferential iron dissolution caused the formation of iron-deficient bornite which was further transformed to $\mathrm{CuS}$ and $\mathrm{Cu}_{3} \mathrm{FeS}_{4}$ due to the diffusion and depletion of labile $\mathrm{Cu}^{+}$ions. Safarzadeh et al. [11] reported that the reactivity of sulfides in sulfuric acid solution followed the order of chalcocite, bornite, enargite, covellite, chalcopyrite and pyrite. Some efforts have also been made to study the dissolution mechanisms of bornite bioleaching. Bevilaqua et al. [12] investigated the oxidative dissolution of bornite by Acidithiobacillus ferrooxidans mainly through $\mathrm{X}$-fray diffraction, and found that CuS, elemental sulfur and jarosite were detected as the secondary phases. Qin et al. [13] used electrochemical analysis to investigate the dissolution process of bornite in the presence of Acidithiobacillus ferrooxidans and Acidithiobacillus caldus, and put forward that CuS, chalcocite $\left(\mathrm{Cu}_{2} \mathrm{~S}\right)$ and nonstoichiometric copper sulfides may be the possible intermediate species. Bevilaqua et al. [14] used electrochemical noise analysis to evaluate the oxidative dissolution of bornite in the absence and presence of Acidithiobacillus ferrooxidans, and found that bacterial activity induced an accelerated corrosion process. They further used electrochemical impedance spectroscopy to monitor bornite oxidation by Acidithiobacillus ferrooxidans, and inferred that $\mathrm{CuS}$ and nonstoichiometric compounds $\left(\mathrm{Cu}_{\mathrm{x}} \mathrm{S}\right)$ were the main intermediate species [15].

The dissolution mechanisms of bornite during bioleaching are extremely important and some studies have been conducted. However, the proposed mechanisms are different, and the specific mechanism is still under debate and not clear. Moderately thermophilic microorganisms are considered to be promising in the future industrial application due to their advantages over mesophilic microorganisms and extremely thermophilic microorganisms [16-18]. The dissolution processes of bornite in bioleaching systems consists of complicated oxidation-reduction reactions which are dependent on the redox potentials. Therefore, density functional theory (DFT) calculations, X-ray photoelectron spectroscopy (XPS) analysis and electrochemistry analysis were combined in this work to analyze the surface transformation and dissolution process of bornite at different applied potentials. Based on the obtained results, the dissolution mechanisms of bornite in the presence of moderately thermophilic microorganisms were further interpreted.

\section{Materials and Methods}

\subsection{DFT Calculation}

A cubic bornite unit cell with space group of F- $43 \mathrm{~m}$ was employed and its lattice parameters are shown in Figure 1 and Table 1, respectively. All DFT computations were performed using the CASTEP module in the Materials Studio 6.0 software package. The PBE density functional was chosen to account for the exchange-correlation potential $[19,20]$. To provide proper descriptions for the interactions between ions and their valence electrons, we adopted the ultrasoft pseudopotentials (USPP), where the valence shells were set to $3 \mathrm{~d}^{6} 4 \mathrm{~s}^{2}, 3 \mathrm{~d}^{10} 4 \mathrm{~s}^{1}$ and $3 \mathrm{~s}^{2} 3 \mathrm{p}^{4}$ for $\mathrm{Fe}, \mathrm{Cu}$ and $\mathrm{S}$ atoms, respectively. It is well known that the $d$ and $f$ electrons of transition metal atoms usually exhibit such strong correlations that an improper computation method often leads to irrational electron structures 
differing largely from experimental results. Accordingly, the Hubbard $+\mathrm{U}$ correction was usually employed [21-23]. In this work, the correction was employed in all energy, property and geometry optimization calculations. The $\mathrm{U}$ values for $\mathrm{Cu}$ and Fe were both 2.5 , which were automatically set by CASTEP. Moreover, spin polarization was also taken into account with the initial spin obtained from the parameters of the aforementioned cubic unit cell model [24].

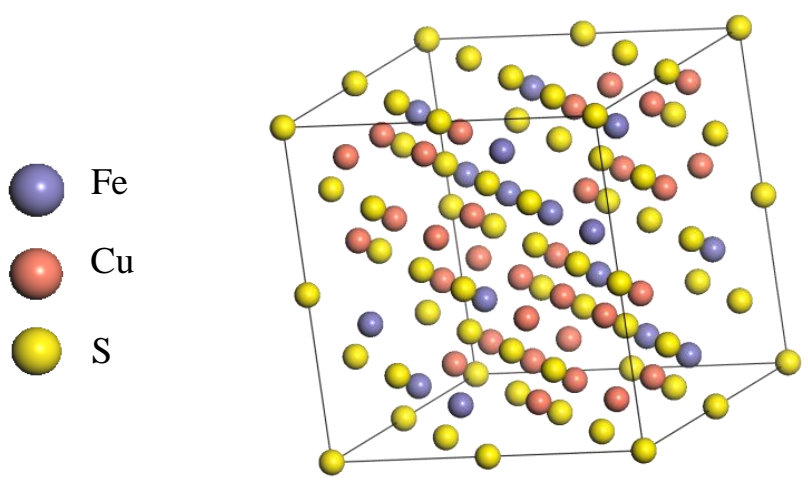

Figure 1. The structure of F-43m bornite in DFT calculation.

Table 1. Lattice constants of the bornite structure in DFT calculation (CASTEP module of Materials Studio 6.0 software package, PBE density function, Hubbard + U correction).

\begin{tabular}{cccc}
\hline Crystal System & Space Groups & Lattice Constant & Crystal Angle \\
\hline Cubic & F-43m & $\mathrm{a}=\mathrm{b}=\mathrm{c}=10.710 \AA$ & $\alpha=\beta=\gamma=90^{\circ}$ \\
\hline
\end{tabular}

During geometry optimizations, the convergence thresholds were set to $1.0 \times 10^{-5} \mathrm{eV} / \mathrm{atom}$, $0.03 \mathrm{eV} / \AA$ and $0.001 \AA$ for the total energies, the max force and the max displacement, respectively. The SCF convergence threshold was $1.0 \times 10^{-6} \mathrm{eV} /$ atom. A $3 \times 3 \times 3$ k-point grid with a $400 \mathrm{eV}$ kinetic energy cutoff was used. After structural relaxations, energy and property calculations were carried out using the same convergence thresholds, integration grids and cutoff.

To model the reconstruction of the (111)-S bornite surface, we adopted the lattice plane sliced from the optimized unit cell (the molar ratio of $\mathrm{Cu}$ : Fe: $\mathrm{S}$ within the plane was retained). Considering the symmetry properties and computational cost, finally we constructed a cell model which has half length of the $a$ and $b$ unit cell vectors and one unit length in the $c$ axis (5 layers in total, the bottom 3 layers were fixed during modelling). To further eliminate the interactions between the top and bottom surface, a vacuum layer of $10 \AA$ was added along the direction of the $c$ axis. The convergence thresholds for modelling surface reconstruction were $2.0 \times 10^{-5} \mathrm{eV} /$ atom, $0.05 \mathrm{eV} / \AA$ and $0.002 \AA$ for the total energies, the max force and the max displacement, respectively. The SCF convergence threshold was set to $2.0 \times 10^{-6} \mathrm{eV} /$ atom. A $3 \times 3 \times 1 \mathrm{k}$-point grid and a $400 \mathrm{eV}$ cutoff were employed. After optimizations (i.e., reconstruction), energy and property calculations were performed using the same convergence thresholds, grids and cutoff.

\subsection{Bioleaching Experiments}

The moderately thermophilic microorganisms Acidithiobacillus caldus (A. caldus) (CCTC AB 206240) and Leptospirillum ferriphilum (L. ferriphilum) (CCTC AB 206239) were both initially acquired from the Key Lab of Bio-hydrometallurgy of the Ministry of Education, Central South University, Changsha, China. Bornite samples of high purity were obtained from Meizhou, Guangdong Province, China. The elements analysis indicates that the pure bornite samples contained $61.59 \% \mathrm{Cu}, 10.04 \%$ Fe and $27.10 \% \mathrm{~S}$ (wt \%), respectively. L. ferriphilum and $A$. caldus were sub-cultured into basal culture medium supplemented with $44.7 \mathrm{~g} / \mathrm{L}$ ferrous sulfate $\left(\mathrm{FeSO}_{4} \cdot 7 \mathrm{H}_{2} \mathrm{O}\right)$ and $10 \mathrm{~g} / \mathrm{L}$ sulfur as energy source, respectively. Mixed culture consisting of L. ferriphilum and A. caldus was sub-cultured into 
basal culture medium supplemented with $44.7 \mathrm{~g} / \mathrm{L}$ ferrous sulfate $\left(\mathrm{FeSO}_{4} \cdot 7 \mathrm{H}_{2} \mathrm{O}\right)$ and $10 \mathrm{~g} / \mathrm{L}$ sulfur as energy sources. When microorganisms grew to their exponential growth phase with cell density of higher than $1.0 \times 10^{8}$ cells $/ \mathrm{mL}$, cells were harvested, centrifuged and washed. The obtained cells were inoculated into a $250-\mathrm{mL}$ shake flask containing $100 \mathrm{~mL}$ of sterilized culture medium and $2 \mathrm{~g}$ of bornite samples. The shake flasks were placed into an orbital shaker at $170 \mathrm{rpm}$ and $45^{\circ} \mathrm{C}, \mathrm{pH}$ was regulated around 1.70 with dilute sulfuric acid, and water lost through evaporation was supplemented with deionized water periodically.

\subsection{Analytic Techniques}

Metal ions concentrations were analyzed by inductively coupled plasma-atomic emission spectrometry (ICP-AES) (PS-6, Baird Co., Deford, MA, USA), meanwhile, $\mathrm{pH}$ and Oxidation-Reduction Potential (ORP) values were monitored with a pH meter (PHSJ-4A, Shanghai LEICI Co., Shanghai, China) and ORP meter (BPH-221, Dalian BELL Co., Dalian, China), respectively. Electrochemistry tests were conducted by conventional three-electrode system (Princeton Model 283 Potentiostat, EG\&G of Princeton Applied Research, Princeton, NJ, USA). All the potential values mentioned were referred to the $\mathrm{Ag} / \mathrm{AgCl}$ electrode (vs. $\mathrm{Ag} / \mathrm{AgCl}$ ) in this work. X-ray photoelectron spectroscopy (XPS) analysis was implemented on a model ESCALAB 250Xi instrument (Thermo Fisher Scientific Co., Waltham, MA, USA). The XPS spectra were recorded at a constant pass energy of $20 \mathrm{eV}$ and $0.1 \mathrm{eV} / \mathrm{step}$ with Al K $\alpha$ X-ray source. The Thermo Avantage 5.52 software (Thermo Fisher Scientific Co.) was used to fit the obtained XPS spectra, binding energies were referred to the C 1s level at $284.8 \mathrm{eV}$, the background of spectra was achieved by using the Shirley method, and the S $2 p$ spectra were fitted by the Gaussian-Lorentzian line (SGL) function [25]. The S $2 p$ spectra were fitted using a 2:1 peak area ratio and $1.2 \mathrm{eV}$ splitting for $\mathrm{S} 2 \mathrm{p}_{3 / 2}$ and $\mathrm{S} 2 \mathrm{p}_{1 / 2}$. To investigate the surface transformation of bornite at different potentials, the bornite electrode was treated by different potentials for $3 \mathrm{~h}$, and the treated bornite electrode was then analyzed by XPS. Bornite samples bioleached by different microorganisms for different numbers of days were analyzed by XPS to reveal the intermediate species on bornite surface during bioleaching.

\section{Results and Discussions}

\subsection{DFT Calculations of the Bornite Surface}

According to symmetry, we converted the unit cell into a primitive cell before our calculation. During our CASTEP calculation, we chose the following 3 parameters to check the convergence according to the energy cutoff and the results are shown in Table 2. The total energy of system changed slightly under 3 different settings of energy cut-off, and the value of $\mathrm{dE}_{\text {tot }} / \mathrm{dE}_{\mathrm{log}}\left(\mathrm{E}_{\mathrm{cut}}\right)$ also meets the requirements. It is noted that the number of SCF iterations under $400 \mathrm{eV}$ decreased significantly. Based on the above, we can reach convergence fast and accurately by setting the energy cutoff at $400 \mathrm{eV}$.

Table 2. Convergence test results of energy cut-off in DFT calculation (CASTEP module of Materials Studio 6.0 software package, PBE density function, Hubbard + U correction).

\begin{tabular}{cccc}
\hline Cut-off Energy/eV & SCF Loops & $\mathbf{d E}_{\text {tot }} / \mathbf{d l o g}\left(\mathrm{E}_{\text {cut }}\right)$ & Final Energy/eV \\
\hline 390 & 115 & - & $-17,491.94660$ \\
395 & 15 & - & $-17,491.94830$ \\
400 & 15 & -0.15371 & $-17,491.95020$ \\
\hline
\end{tabular}

Table 3 shows the lattice parameters before and after optimization and the reference results. The relative error between the optimized lattice parameters and the reference results was $3.2 \%$ [24]. In combination with the results of convergence test, the optimization results were convincing. It can 
represent the actual structure of F-43m bornite. The consideration of spin and LDA + U corrections made our computations more reliable.

Table 3. Results of cell parameters optimization in DFT calculation and reference (CASTEP module of Materials Studio 6.0 software package, PBE density function, Hubbard + U correction).

\begin{tabular}{cccc}
\hline Parameter & Reference & Optimization Result & Relative Error/\% \\
\hline $\mathrm{a}=\mathrm{b}=\mathrm{c}$ & $10.710 \AA$ & $11.0503 \AA$ & 3.2 \\
$\alpha=\beta=\gamma$ & $90^{\circ}$ & $90^{\circ}$ & - \\
\hline
\end{tabular}

To analyze various kinds of properties of the F-43m bornite, we calculated the vacuum single point energy of the optimized structure. As shown in Table 4, we can get the analytical results of $\mathrm{Cu}$, Fe, $\mathrm{S}$ atom orbital and total Mulliken population. From this table, we can see that the Fe atom transferred 0.46 electrons to the $S$ atom (the electron cloud on Fe atom skewed to the $\mathrm{S}$ atom), part of the Cu atoms (Cu1-4) transferred 0.06 electrons to the $\mathrm{S}$ atom, while another part of the $\mathrm{Cu}$ atoms (Cu4-8) transferred 0.17 electrons to the $\mathrm{S}$ atom. These two different kinds of $\mathrm{Cu}$ atoms in different chemical environments suggested that the $\mathrm{Cu}$ atoms in F-43m bornite may exist in two different oxidation states.

Table 4. Mulliken population of bornite in DFT calculation (CASTEP module of Materials Studio 6.0 software package, PBE density function, Hubbard + U correction).

\begin{tabular}{cccccccc}
\hline Species & Ion & $\mathbf{s}$ & $\mathbf{p}$ & $\mathbf{d}$ & Total & Charge/e & Spin/hbar \\
\hline $\mathrm{S}$ & 1 & 1.79 & 4.56 & 0.00 & 6.34 & -0.34 & 0.04 \\
$\mathrm{~S}$ & 2 & 1.85 & 4.54 & 0.00 & 6.39 & -0.39 & 0.13 \\
$\mathrm{~S}$ & 3 & 1.79 & 4.55 & 0.00 & 6.33 & -0.33 & 0.12 \\
$\mathrm{~S}$ & 4 & 1.79 & 4.55 & 0.00 & 6.34 & -0.34 & 0.10 \\
$\mathrm{~S}$ & 5 & 1.79 & 4.55 & 0.00 & 6.33 & -0.33 & 0.12 \\
$\mathrm{~S}$ & 6 & 1.79 & 4.55 & 0.00 & 6.34 & -0.34 & 0.10 \\
$\mathrm{~S}$ & 7 & 1.79 & 4.55 & 0.00 & 6.33 & -0.33 & 0.12 \\
$\mathrm{~S}$ & 8 & 1.79 & 4.55 & 0.00 & 6.34 & -0.34 & 0.10 \\
$\mathrm{Fe}$ & 1 & 0.36 & 0.64 & 6.54 & 7.54 & 0.46 & 1.70 \\
$\mathrm{Fe}$ & 2 & 0.36 & 0.64 & 6.54 & 7.54 & 0.46 & 1.70 \\
$\mathrm{Fe}$ & 3 & 0.36 & 0.64 & 6.54 & 7.54 & 0.46 & 1.70 \\
$\mathrm{Fe}$ & 4 & 0.34 & 0.60 & 6.54 & 7.54 & 0.46 & 1.67 \\
$\mathrm{Cu}$ & 1 & 0.60 & 0.56 & 6.54 & 10.95 & 0.05 & 0.00 \\
$\mathrm{Cu}$ & 2 & 0.59 & 0.55 & 6.60 & 10.94 & 0.06 & 0.00 \\
$\mathrm{Cu}$ & 3 & 0.59 & 0.55 & 9.79 & 10.94 & 0.06 & 0.00 \\
$\mathrm{Cu}$ & 4 & 0.59 & 0.55 & 9.79 & 10.94 & 0.06 & 0.00 \\
$\mathrm{Cu}$ & 5 & 0.49 & 0.50 & 9.79 & 10.82 & 0.18 & 0.04 \\
$\mathrm{Cu}$ & 6 & 0.50 & 0.50 & 9.79 & 10.83 & 0.17 & 0.04 \\
$\mathrm{Cu}$ & 7 & 0.50 & 0.50 & 9.84 & 10.83 & 0.17 & 0.04 \\
$\mathrm{Cu}$ & 8 & 0.50 & 0.50 & 9.83 & 10.83 & 0.17 & 0.04 \\
\hline
\end{tabular}

Further analysis of the electronic structure of the whole cell of the F-43m bornite, especially the different oxidation states of the $\mathrm{Cu}$ atoms, as well as the bond population analysis is listed in Table 5 . The value of the bond population reflects the degree of the bond covalence. The bond covalence increased with the increase of bond population value, and it's completely a covalent bond when the value is equal to 1 . When the value is equal to 0 , it represents a completely ionic bond. The bonding between $S$ and $M$ (stand for metal) atoms in bornite was very complicated. The Cu1-4 not only bonded with the S atoms, but also had interactions with Fe atoms. (Cu1-4) transferred less electrons to the S atoms due to the covalency, thus causing Cu1-4 atoms existed in different chemical environments and with different oxidation states.

From the energy band diagram (Figure 2) of the F-43m bornite, we can find that the F- $43 \mathrm{~m}$ bornite is a conductor with metallic conductivity because its energy gap was almost $0 \mathrm{eV}$. This verified the $\mathrm{Cu}$-Fe bonding effect in bond population analysis, whose behavior was similar to the electrons in metals. 
Table 5. Binding energy and FWHM value for XPS spectra of $S 2 p_{3 / 2}$ peaks of bornite after treating by different potential of $0,0.3,0.45,0.55,0.65 \mathrm{~V}$, respectively (Implemented on the model of ESCALAB 250Xi of $\mathrm{Al} \mathrm{K} \alpha$ X-ray source with $20 \mathrm{eV}$ constant pass energy and $0.1 \mathrm{eV} /$ step; Fitted by Thermo Avantage 5.52, C 1s $284.8 \mathrm{eV}$ as reference, Shirley method, Gaussian-Lorentzian function) (FWHM means full width at half maximum, B.E. means binding energy value).

\begin{tabular}{ccccc}
\hline \multirow{2}{*}{ Conditions (vs. Ag/AgCl) } & Peak 1 & Peak 2 & \multicolumn{2}{c}{ Peak 3 } \\
\cline { 2 - 5 } & B.E. (eV) & B.E. (eV) & B.E. (eV) & FWHM (eV) \\
\hline $0 \mathrm{~V}$ & 161.3 & 162.3 & - & - \\
$0.3 \mathrm{~V}$ & 161.4 & 162.1 & 163.2 & 1.4 \\
$0.45 \mathrm{~V}$ & 161.4 & 162.2 & 163.4 & 1.4 \\
$0.55 \mathrm{~V}$ & 161.4 & 162.2 & 163.6 & 1.0 \\
$0.65 \mathrm{~V}$ & 161.5 & - & 163.6 & 1.0 \\
\hline
\end{tabular}

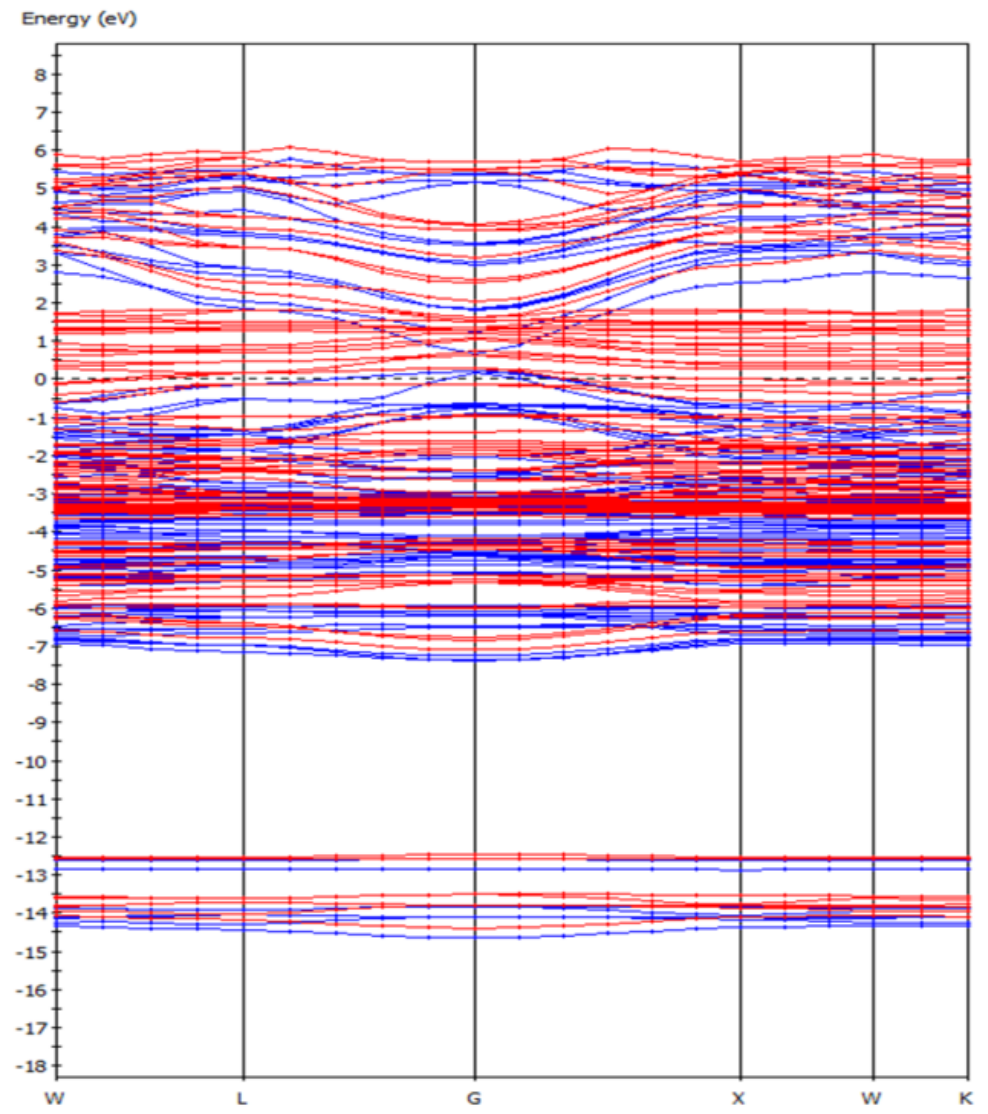

Figure 2. The band structure of bornite (X-axis, High symmetry point; Y-axis, Energy/eV) in DFT calculation (CASTEP module of Materials Studio 6.0 software package, PBE density function, Hubbard + U correction).

Figure 3 shows the total density of state (DOS) and the partial density of state (PDOS) of the $\mathrm{Cu}, \mathrm{Fe}$, and $\mathrm{S}$ atoms. We can find that the bottom of the valence bond band from -15.0 to $-12.0 \mathrm{eV}$ was mainly made up of the 3 s orbital of $S$ atoms. Lying between -8.0 and $0 \mathrm{eV}$ were contributions of the combination of the $3 \mathrm{~d}$ orbitals of $\mathrm{Cu}$ Atoms, $3 \mathrm{~d}$ orbitals of Fe atom and $3 \mathrm{p}$ orbitals of $\mathrm{S}$ atoms. The conduction band between 0 and $2 \mathrm{eV}$ consisted of $3 \mathrm{~d}$ orbitals of Fe atoms. The higher energy part was made up of the 4 s orbital of $\mathrm{Cu}$ atom, $3 p$ orbital of $\mathrm{Cu}$ atom, 4 s orbital of Fe atom, 3p orbital of Fe atom and $3 p$ orbital of $S$ atom. The existence of the electrical conductivity was mainly due to the $3 \mathrm{~d}$ orbitals of Fe atoms crossed over the Fermi level and interacted with the high-level orbitals of $\mathrm{Cu}$ atoms. Thus, the most active atoms in the F-43m bornite unit cell were the Fe atoms. 

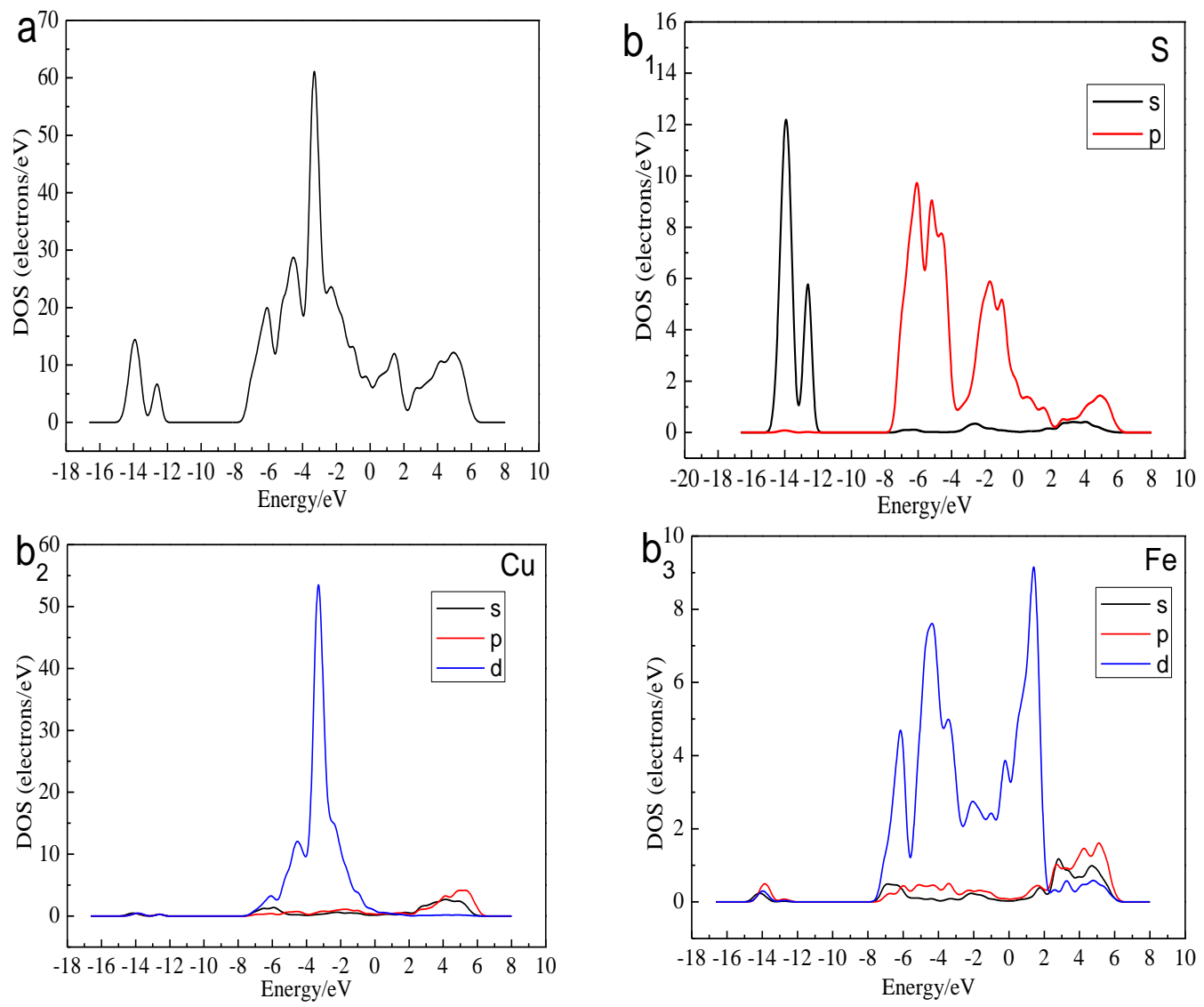

Figure 3. DOS and PDOS of bornite in DFT calculation (CASTEP module of Materials Studio 6.0 software package, PBE density function, Hubbard + U correction): $(\mathbf{a})$ Total; $\left(\mathbf{b}_{\mathbf{1}}\right) \mathrm{Cu}$; $\left(\mathbf{b}_{\mathbf{2}}\right) \mathrm{Fe}$; $\left(\mathbf{b}_{3}\right) \mathrm{S}$.

Figure 4 shows the changes of the (111)-S surface during the surface reconstruction.
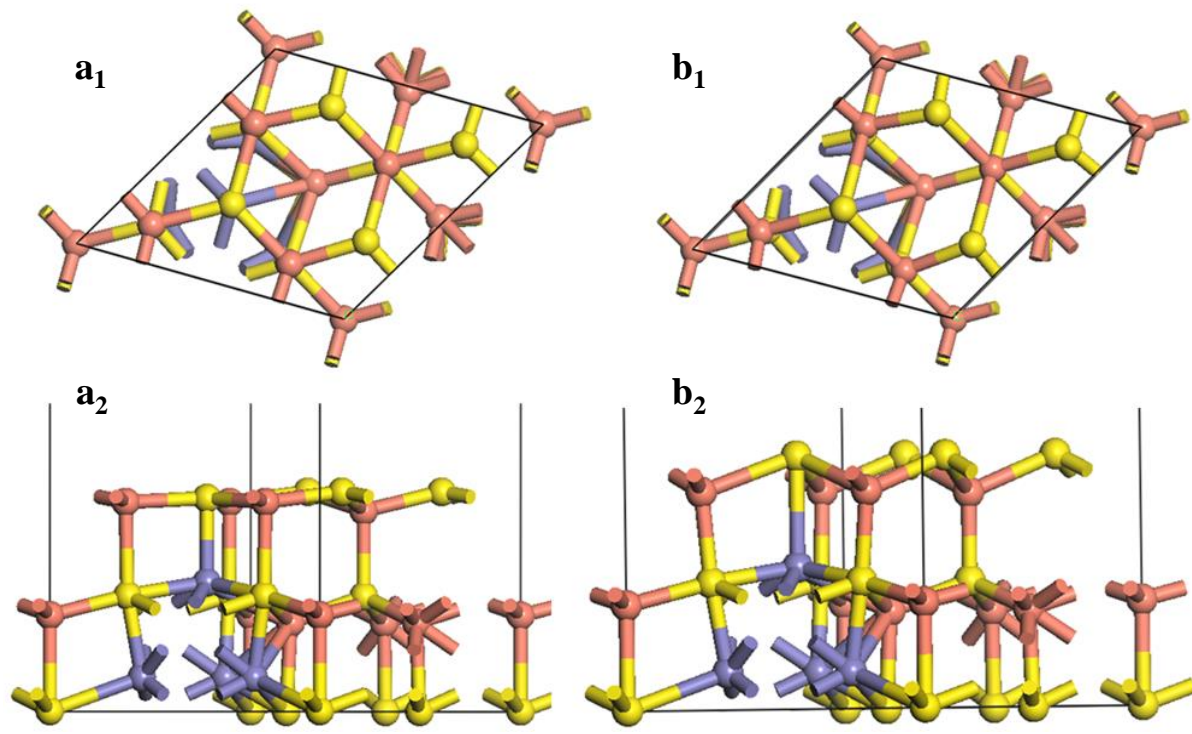

Figure 4. Reconstruction of bornite (111)-S surface in DFT calculation (CASTEP module of Materials

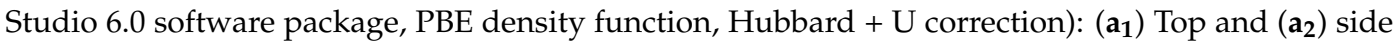
views of optimized (111)-S surface; ( $\left.\mathbf{b}_{\mathbf{1}}\right)$ Top and $\left(\mathbf{b}_{\mathbf{2}}\right)$ side views of initial (111)-S surface. 
At the F-43m bornite's (111)-S surface, the first layer consisted of $4 \mathrm{~S}$ atoms, while the second layer was made up of $4 \mathrm{Cu}$ atoms. After the surface relaxation, large variation occurred on the surface S-Cu bond. The bond length was reduced from $2.65696 \AA$ to $2.33817 \AA$. The inter-layer angle of $\mathrm{Cu}-\mathrm{S}-\mathrm{Cu}$ changed from $109.471^{\circ}$ to $119.785^{\circ}$. The original two layers were almost rearranged to be a new layer. The bond length of the $\mathrm{S}$ atom in the third layer and the $\mathrm{Cu}$ atom in the surface floor extended from $2.29674 \AA$ to $2.59200 \AA$ after optimization. Such a Cu-S bond was easier to break caused by surface reactions. The bond length of the Fe atom in the third layer and the $S$ atom in the surface was reduced from $2.80266 \AA$ to $2.33817 \AA$ after optimization. Such a change of the surface morphology resulted in some variations of the reactivity of atoms. The inner core $\mathrm{Cu}$ atoms were exposed, making them easier to react with chemicals. The shortening of the Fe-S bond enhanced the Fe-S bond covalence, reducing the reaction activity of the Fe atoms.

Figure 5 exhibits the electron density population of the first shell atoms of the (111)-S surface before and after optimization. The bonding overlap of $\mathrm{Cu}-\mathrm{S}$ revealed that the inner $\mathrm{Cu}$ atoms were exposed to the surface after relaxation, leading to the increase of electron density on the surface. This facilitated the reaction between reactant and the bornite (111)-S surface. In other words, the (111)-S surface lost electrons and the reactant obtained electrons, making the bornite (111)-S surface oxidized.
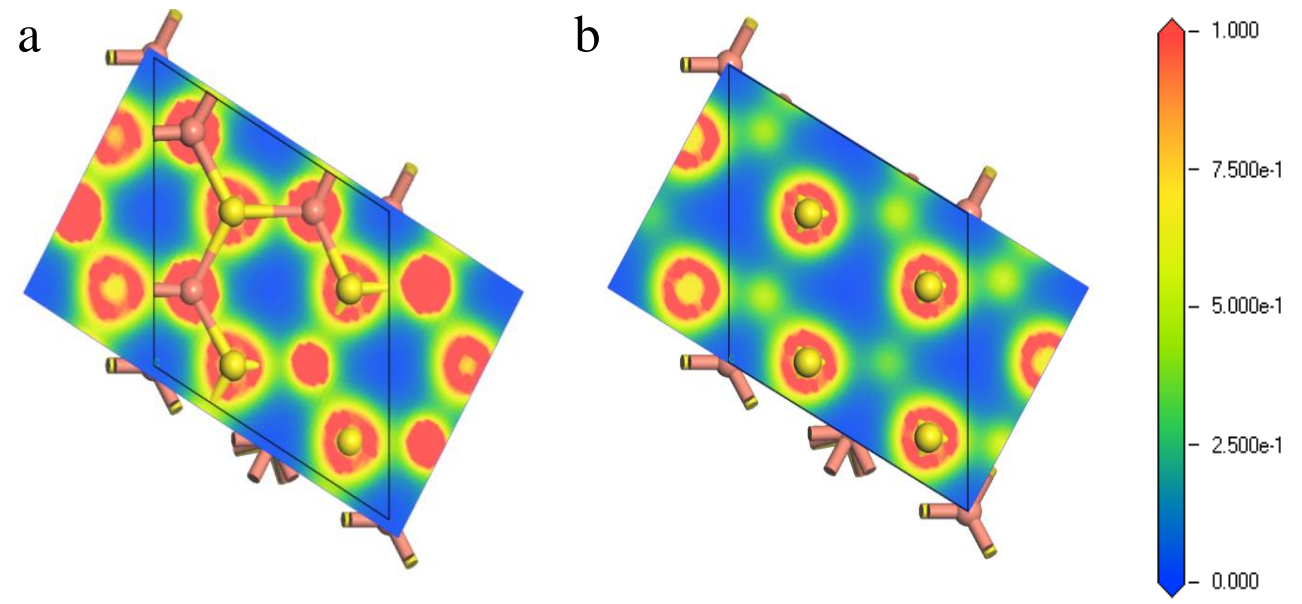

Figure 5. Electron density of bornite (111)-S surface before and after reconstruction in DFT calculation (CASTEP module of Materials Studio 6.0 software package, PBE density function, Hubbard + U correction): (a) The first layer of optimized (111)-S surface; (b) The first layer of initial (111)-S surface.

Figure 6 shows the electron density of the Fe-S bond from the core Fe atoms and the surface $S$ atoms at (111)-S surface. It can be seen from Figure 6 that the bonding overlaps of the surface $S$ atoms and inner Fe atoms became larger after relaxation, implying that tighter bonding occurred between the inner Fe atoms and the surface $S$ atoms. Thus, the corresponding Fe-S bonds were relatively hard to break, causing that during the initial stages of chemical reactions on the (111)-S surface, and the inner irons can hardly participate.

Analysis of the local density of states (LDOS) of the surface $\mathrm{Cu}$ and $\mathrm{S}$ atoms, and inner iron atoms is shown in Figure 7. By comparing the total values of LDOS before and after relaxation, we can see that the DOS of (111)-S plane decreased within the -1 to $0 \mathrm{eV}$ energy range. This suggested an oxidation process occurred during relaxation. If we look more in detail into the DOS of various surface atoms $(\mathrm{Cu}, \mathrm{Fe}$ and $\mathrm{S})$, within the range of -1 to $0 \mathrm{eV}$ : the DOS of iron atoms increased, copper atoms decreased slightly, and sulfur atoms diminished substantially. It clearly demonstrated that the Fe atoms obtained negative charges (i.e., electrons) from the $\mathrm{S}$ atoms and $\mathrm{Cu}$ atoms. In other words, the $\mathrm{Cu}$ and $\mathrm{S}$ atoms were oxidized while the Fe atoms were reduced. This corresponds well to the aforementioned analysis of electron densities. 
a

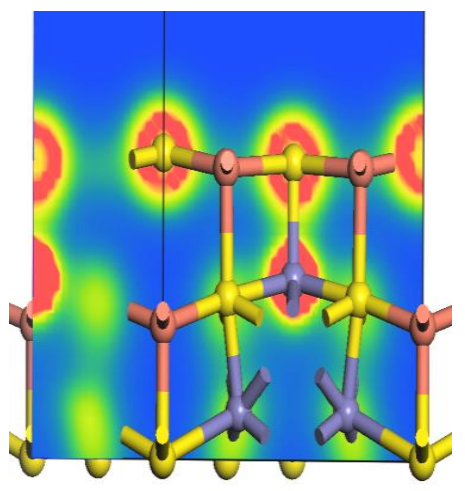

$\mathrm{b}$

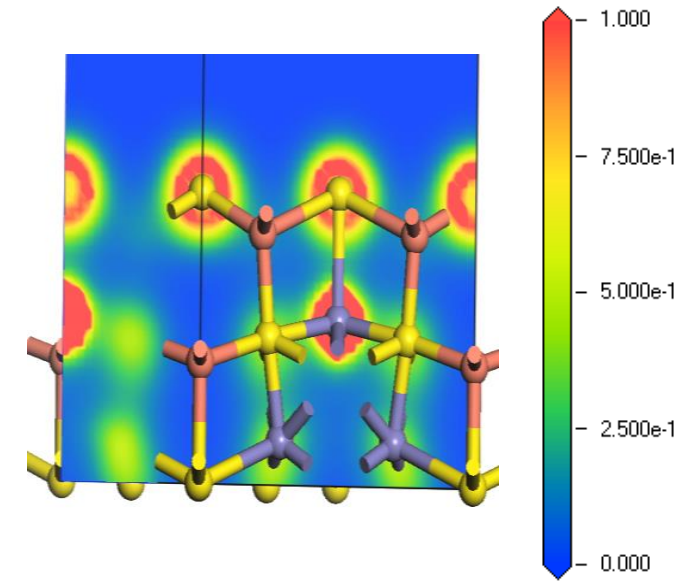

Figure 6. Electron density of Fe-S bond of bornite (111)-S surface before and after reconstruction in DFT calculation (CASTEP module of Materials Studio 6.0 software package, PBE density function, Hubbard + U correction): (a) The optimized Fe-S bond; (b) The initial Fe-S bond.
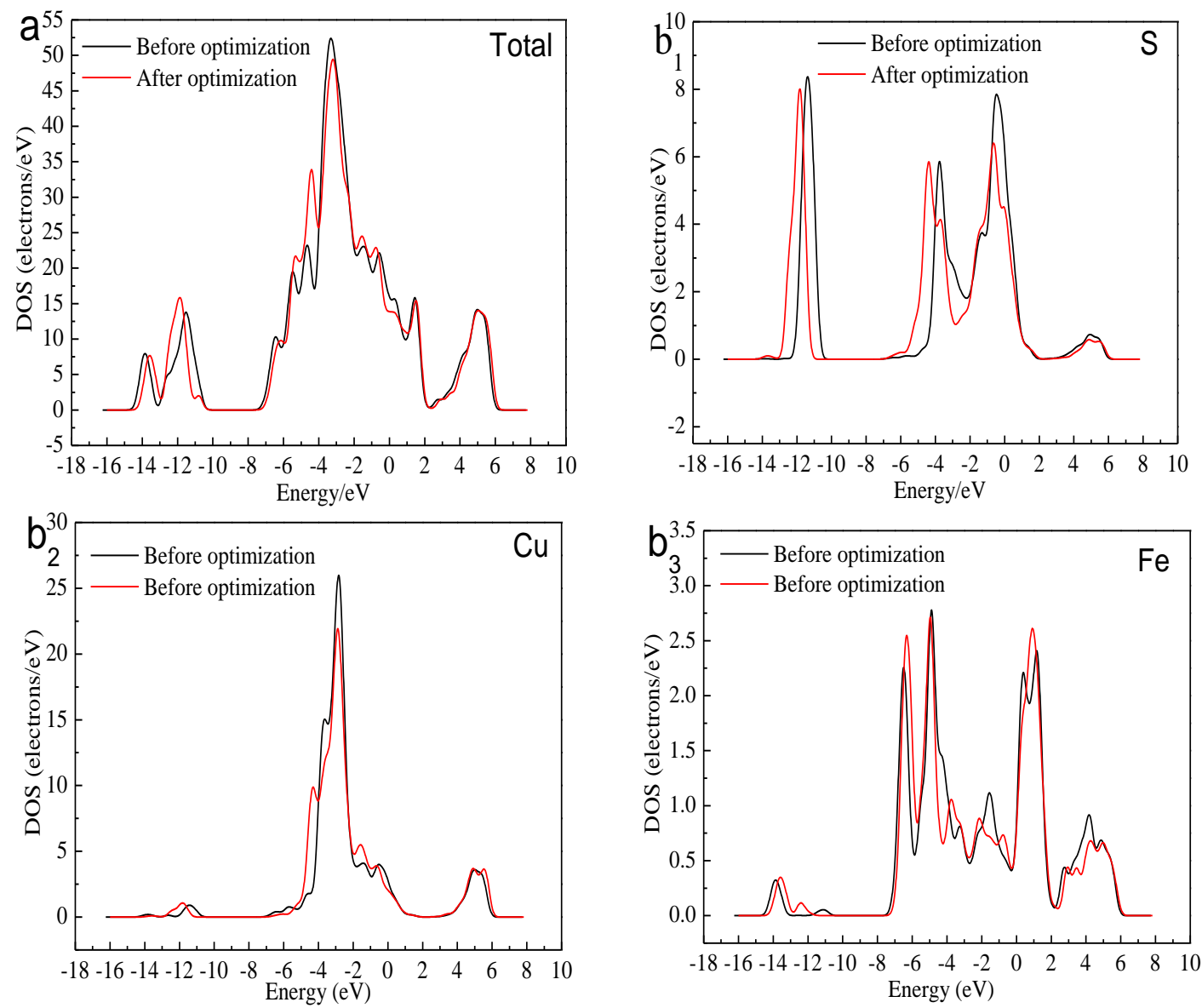

Figure 7. Local DOS of bornite before and after optimization (CASTEP module of Materials Studio 6.0 software package, PBE density function, Hubbard + U correction): (a) Total; $\left(\mathbf{b}_{\mathbf{1}}\right) \mathrm{S} ;\left(\mathbf{b}_{\mathbf{2}}\right) \mathbf{C u} ;\left(\mathbf{b}_{3}\right) \mathrm{Fe}$ in DFT calculation.

\subsection{Surface Transformation of Bornite at Different Potentials}

Electrochemistry analysis was carried out to interpret the electrochemical dissolution processes of bornite. The cyclic voltammograms of bornite in positive scan route and negative scan route are 
presented in Figure 8. Peaks a, b and c were considered as a continuous process composed of the formation and further oxidation of $\mathrm{Cu}_{2} \mathrm{~S}$ [26-29]. Peak c can also represent the oxidation of hydrogen sulfide to elemental sulfur as shown in Equation (4) [27,30]. Peak d was the decomposition of bornite as shown in Equation (5) [26]. Peak e was considered to be the reduction of $\mathrm{Fe}^{3+}$ and bornite shown in Equations (6) and (7) $[27,31,32]$. Peak $f$ should be the reduction of $\mathrm{Cu}_{2} \mathrm{~S}$ to metal copper $[31,33]$ :

$$
\begin{gathered}
2 \mathrm{Cu}+\mathrm{HS}^{-} \rightarrow \mathrm{Cu}_{2} \mathrm{~S}+\mathrm{H}^{+}+2 \mathrm{e}^{-} \\
\mathrm{Cu}_{2} \mathrm{~S} \rightarrow \mathrm{Cu}_{2-\mathrm{x}} \mathrm{S}+\mathrm{xCu}^{2+}+2 \mathrm{xe}^{-} \\
\mathrm{Cu}_{2-\mathrm{x}} \mathrm{S} \rightarrow \mathrm{CuS}+(1-\mathrm{x}) \mathrm{Cu}^{2+}+2(1-\mathrm{x}) \mathrm{e}^{-} \\
\mathrm{H}_{2} \mathrm{~S} \rightarrow \mathrm{S}^{0}+2 \mathrm{H}^{+}+2 \mathrm{e}^{-} \\
2 \mathrm{Cu}_{5} \mathrm{FeS}_{4}+6 \mathrm{H}^{+} \rightarrow \mathrm{CuS}+(4-\mathrm{x}) \mathrm{Cu}^{2+}+3 \mathrm{H}_{2} \mathrm{~S}+\mathrm{Fe}^{3+}+(5-\mathrm{x}) \mathrm{e}^{-} \\
\mathrm{Fe}^{3+}+\mathrm{e}^{-} \rightarrow \mathrm{Fe}^{2+} \\
2 \mathrm{Cu}_{5} \mathrm{FeS}_{4}+6 \mathrm{H}^{+}+2 \mathrm{e}^{-} \rightarrow 5 \mathrm{Cu}_{2} \mathrm{~S}+3 \mathrm{H}_{2} \mathrm{~S}+2 \mathrm{Fe}^{2+} \\
\mathrm{Cu}_{2} \mathrm{~S}+\mathrm{H}^{+}+2 \mathrm{e}^{-} \rightarrow 2 \mathrm{Cu}+\mathrm{HS}^{-}
\end{gathered}
$$
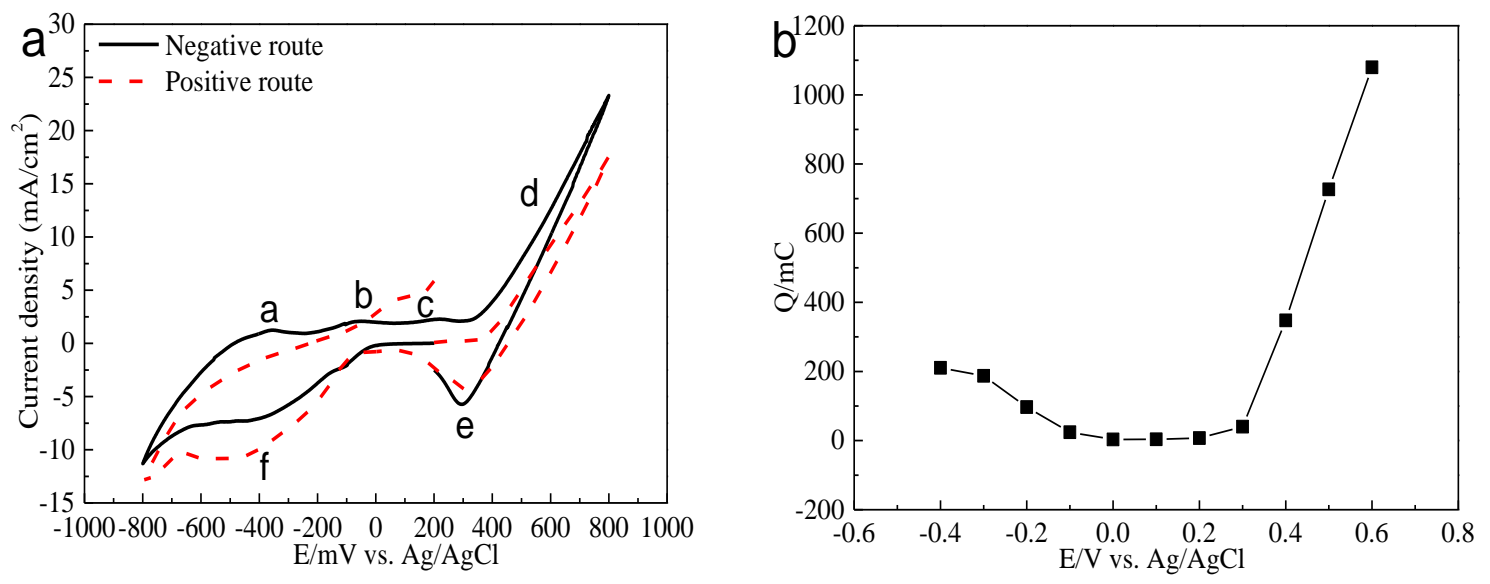

Figure 8. Electrochemistry analysis of bornite in $9 \mathrm{~K}$ bacterial culture medium (Conventional three-electrode system on a Princeton Model 283 Potentiostat, EG\&G of Princeton Applied Research): (a) Cyclic voltammograms of bornite electrode (Scan rate $20 \mathrm{mV} / \mathrm{s}$ ); (b) Relationship between the total charges (evaluated from the current-time curves with duration time of $240 \mathrm{~s}$ ) and applied potentials.

The relationship between the total charge (Figure 8) and applied potential was calculated based on potentiostatic polarization testes. It was found that bornite has a high conductivity, especially at relatively high potentials. The oxidation rate was significantly higher than the reduction rate, indicating that bornite tended to be directly oxidized. This was different with chalcopyrite which was difficult to be oxidized and $\mathrm{Ag}^{+}$is required to enhance the oxidation rate [34,35].

Bornite electrode was treated by different potentials for $3 \mathrm{~h}$ to further investigate the electrochemical dissolution process of bornite. Figure 9 shows the current-time curves of bornite electrode at different applied potentials for $3 \mathrm{~h}$. The curves sharply declined and then kept steady, indicating that the oxidation reactions of bornite reached chemical equilibrium. Figure 10 presents the open circuit potentials (OCP) of bornite after treating by different potentials. The values of OCP significantly increased with the increase of applied potentials, indicating that higher potential was required to further oxidize the formed oxidation species on bornite surface. This may be mainly attributed to the accumulation of oxidation species on bornite species with the increase of potential. 


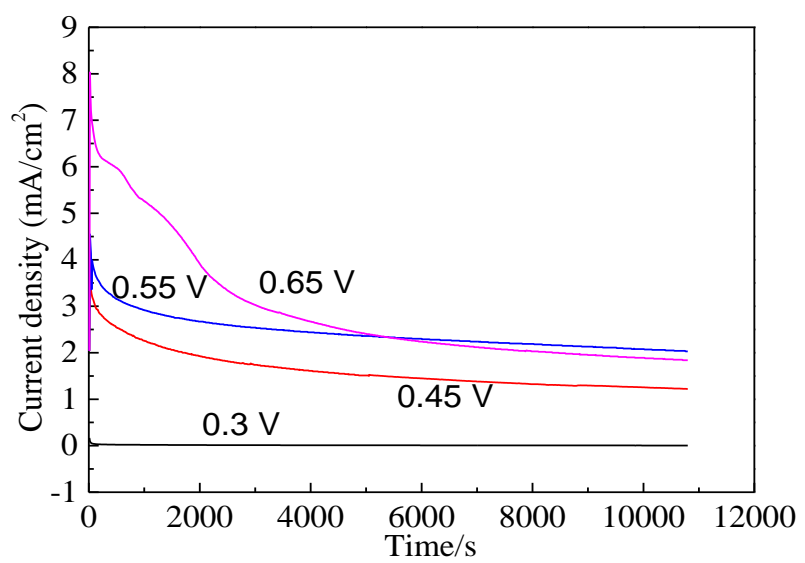

Figure 9. Current-time curves of bornite electrode at different applied potentials for $3 \mathrm{~h}$ in $9 \mathrm{~K}$ bacterial culture medium (Conventional three-electrode system on a Princeton Model 283 Potentiostat, EG\&G of Princeton Applied Research).

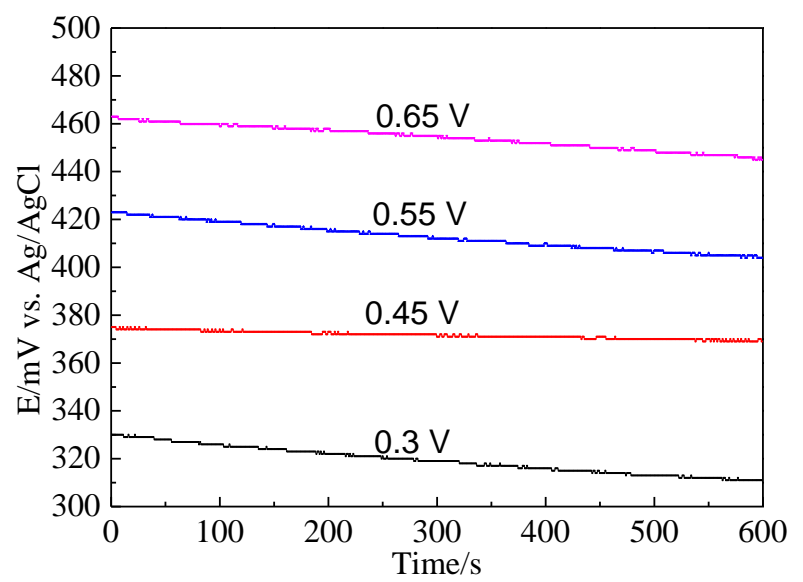

Figure 10. The open circuit potential of bornite electrode after treating by different potentials for $3 \mathrm{~h}$ in $9 \mathrm{~K}$ bacterial culture medium (Conventional three-electrode system on a Princeton Model 283 Potentiostat, EG\&G of Princeton Applied Research).

XPS was used to analyze the surface species of bornite after treating by different potentials, including copper-containing, iron-containing, sulfur-containing and oxygen-containing species. Figure 11 shows the XPS spectra of $\mathrm{Cu}$ peaks of bornite surface after treatment at different potentials, including $\mathrm{Cu} 2 \mathrm{p}$ peaks and $\mathrm{Cu}$ LMM peaks. It was reported that $\mathrm{Cu} 2 \mathrm{p}_{3 / 2}$ peak with a shake-up peak (at about 939-944 eV) was the major XPS characteristic of cupric species $\left(\mathrm{Cu}^{2+}\right)$, and the $\mathrm{Cu} 2 \mathrm{p}_{3 / 2}$ peak without shake-up peak was the characteristics of cuprous species $\left(\mathrm{Cu}^{+}\right)$[36]. It can be found that all the $\mathrm{Cu} 2 \mathrm{p}_{3 / 2}$ peaks of bornite were centered at $932.2 \mathrm{eV}$ without shake-up peak, which was in accordance with the reported value of bornite [36,37]. Therefore, the elemental $\mathrm{Cu}$ of bornite should mainly exist in the valence state of +1 . The $\mathrm{Cu} 2 \mathrm{p}_{3 / 2}$ peaks of bornite surface after treating by different potentials were all centered at 932.2-932.4 eV, which were in accordance with the binding energy of CuS [38]. In addition, the values of binding energy increased with the increase of applied potentials, indicating that $\mathrm{Cu}$ element of bornite tended to be oxidized due to the increase of applied potentials. Cu LMM peaks of bornite after treating by different potentials were all centered at 568.5-569.0 eV, which agreed well with the reported value of CuS [39]. Hence, CuS should be the possible intermediate copper containing species on bornite surface during the oxidation process. 

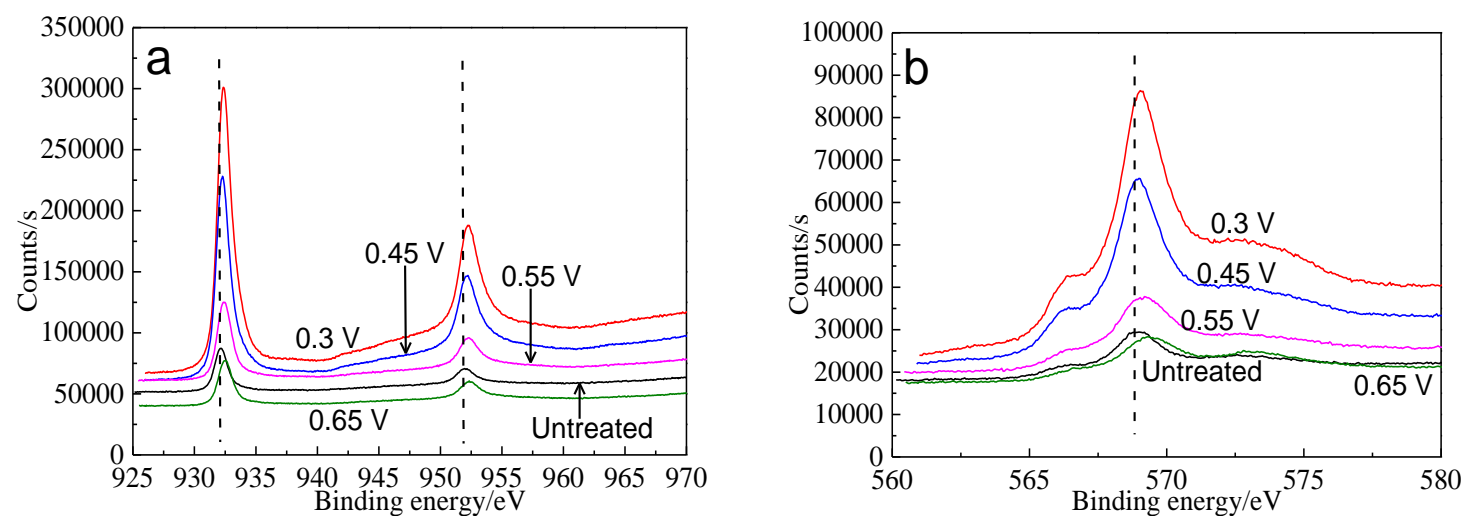

Figure 11. XPS spectra of $\mathrm{Cu}$ peaks of bornite surface after treating by different potential of $0,0.3,0.45$, 0.55, 0.65 V, respectively: (a) Cu 2p peak; (b) Cu LMM peak (Implemented on the model of ESCALAB 250Xi of Al K $\alpha$ X-ray source with $20 \mathrm{eV}$ constant pass energy and $0.1 \mathrm{eV} /$ step; Fitted by Thermo Avantage 5.52, C 1s $284.8 \mathrm{eV}$ as reference, Shirley method, Gaussian-Lorentzian function).

The Fe $3 p$ spectra of bornite surface after treatment at different potentials are presented in Figure 12. Two main peaks can be detected at about 53.0-53.6 eV and 55.5-56.5 eV, respectively. The first peak centered at 53.0-53.6 eV can be assigned to $\mathrm{Fe}^{2+}$ bonded to sulfur in the species of $\mathrm{FeS}_{2}$ or FeS, while the second peak centered at $55.5-56.5 \mathrm{eV}$ can be associated with $\mathrm{Fe}^{3+}$ in $\mathrm{FeOOH}$ [40]. Hence, Fe-S species and $\mathrm{FeOOH}$ should be the possible intermediate iron containing species during the oxidation process of bornite. Additionally, the percentage of $\mathrm{FeOOH}$ in iron containing species increased with the increase of applied potentials from analyzing the peak area.
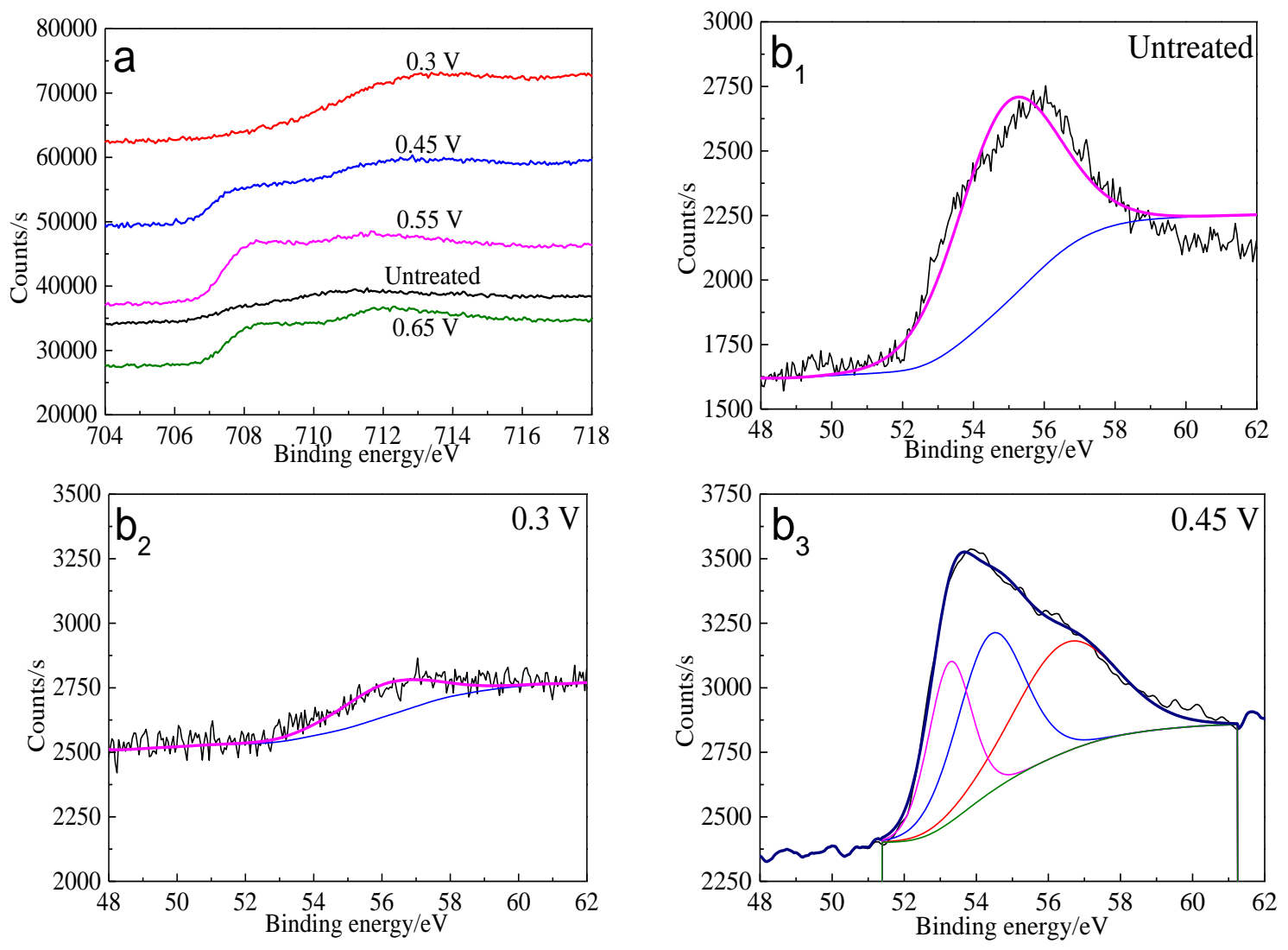

Figure 12. Cont. 

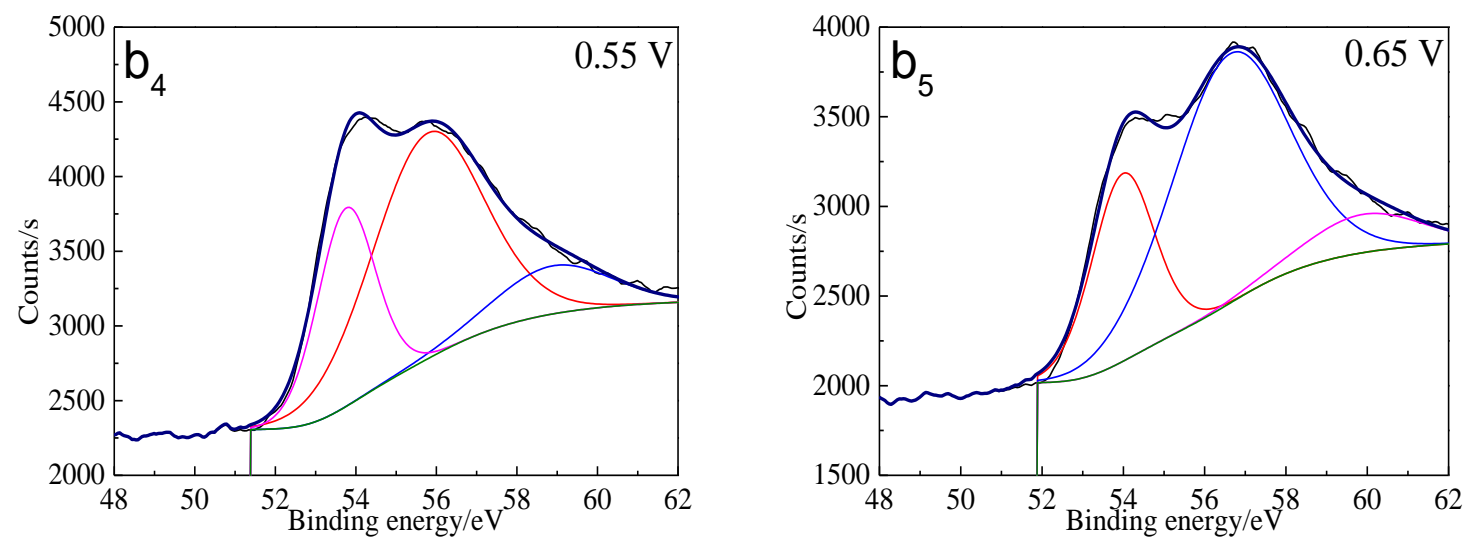

Figure 12. XPS spectra of Fe peaks of bornite surface after treating by different potential of $0,0.3$, $0.45,0.55,0.65 \mathrm{~V}$, respectively: (a) Fe 2p peak; $\left(\mathbf{b}_{1}-\mathbf{b}_{5}\right)$ : Fe 3p peak (Implemented on the model of ESCALAB 250Xi of Al K $\alpha$ X-ray source with $20 \mathrm{eV}$ constant pass energy and $0.1 \mathrm{eV} /$ step; Fitted by Thermo Avantage 5.52, C 1s $284.8 \mathrm{eV}$ as reference, Shirley method, Gaussian-Lorentzian function).

The $S 2 p$ peaks were fitted (Figure 13) and the $S 2 p_{3 / 2}$ values of binding energy and full width at half maximum (FWHM) are presented in Table 5. The types of sulfur containing species can be obtained by comparing with the references [41-45]. It can be found that monosulfide $\left(\mathrm{S}^{2-}\right)$ and disulfide $\left(\mathrm{S}_{2}{ }^{2-}\right)$ were the main sulfur containing species on untreated bornite surface. $\mathrm{S}^{2-}, \mathrm{S}_{2}{ }^{2-}$ and elemental sulfur $\left(\mathrm{S}^{0}\right)$ were the main sulfur containing species on bornite surface after treatment with different potentials, indicating that $\mathrm{S}^{2-}$ and $\mathrm{S}_{2}{ }^{2-}$ can be oxidized to $\mathrm{S}^{0}$ when potential was higher than $0.3 \mathrm{~V} \mathrm{vs}$. $\mathrm{Ag} / \mathrm{AgCl}$.
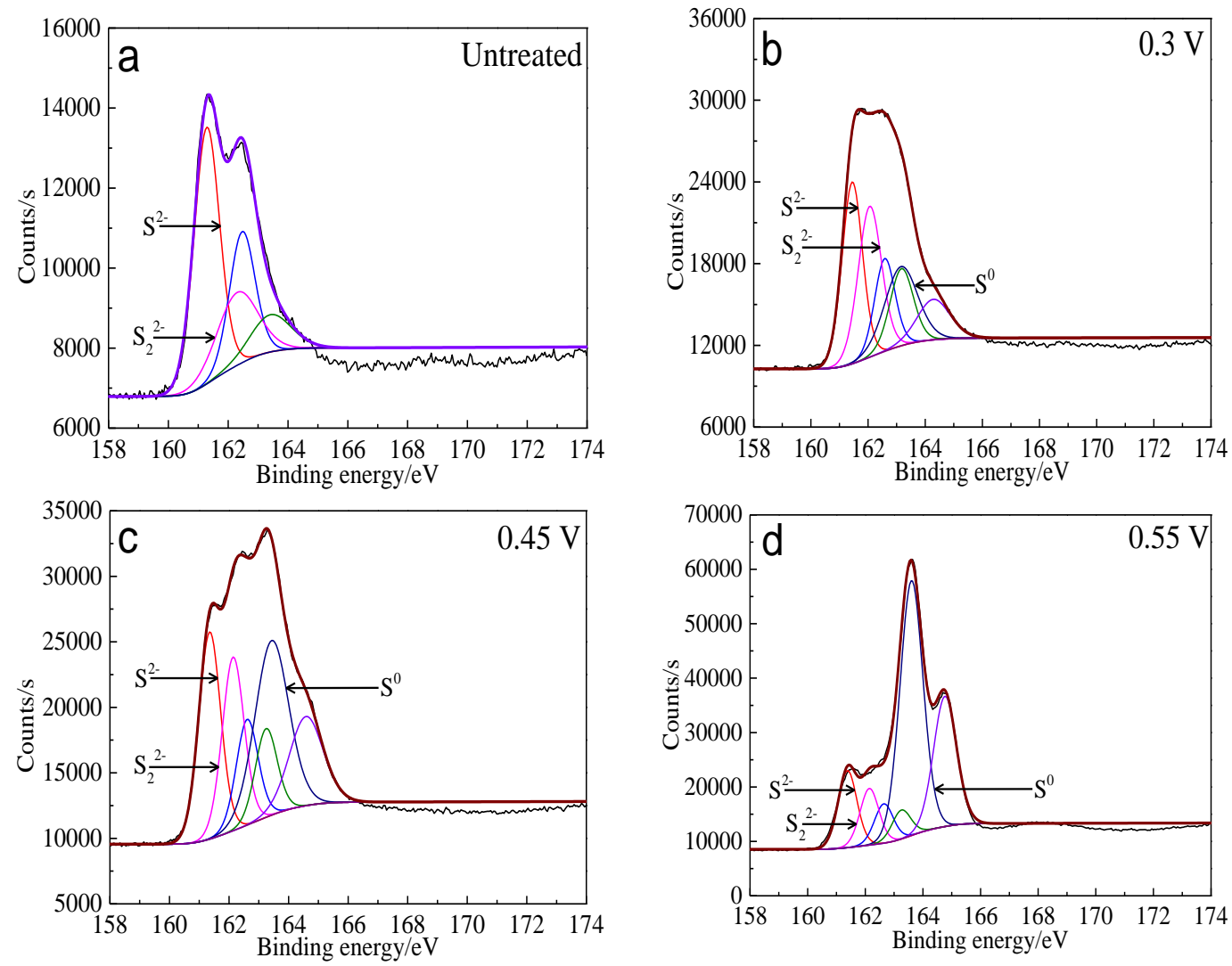

Figure 13. Cont. 


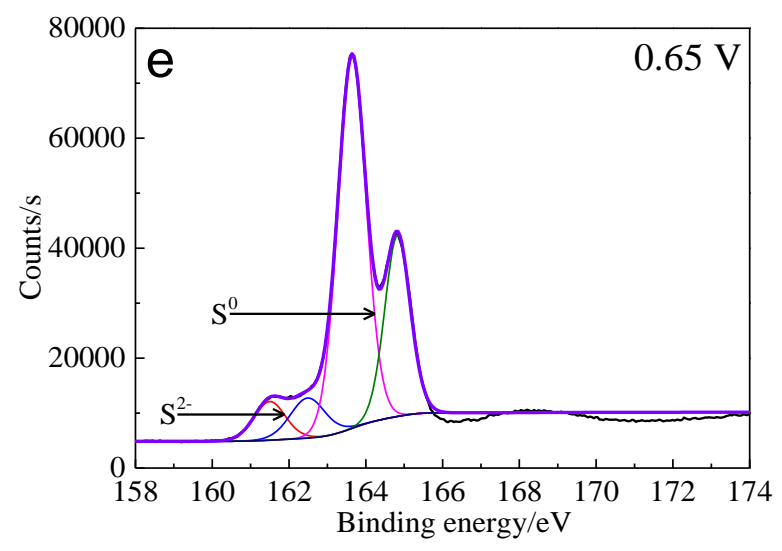

Figure 13. XPS spectra of $S 2 p$ peaks of bornite surface after treating by different potential of $0,0.3,0.45$, 0.55, 0.65 V, respectively: (a) Untreated; (b) $0.3 \mathrm{~V}$; (c) $0.45 \mathrm{~V}$; (d) $0.55 \mathrm{~V}$; (e) 0.65V (Implemented on the model of ESCALAB 250Xi of Al K $\alpha$ X-ray source with $20 \mathrm{eV}$ constant pass energy and $0.1 \mathrm{eV} / \mathrm{step}$; Fitted by Thermo Avantage 5.52, C 1s $284.8 \mathrm{eV}$ as reference, Shirley method, Gaussian-Lorentzian function).

The percentages of sulfur containing species on bornite surface after treatment with different potentials were calculated from the peak areas, which are shown in Figure 14. It can be found that the total percentage of $\mathrm{S}^{2-}$ and $\mathrm{S}_{2}{ }^{2-}$ decreased significantly from $100 \%$ to about $10 \%$, and the proportion of $\mathrm{S}^{0}$ increased obviously from 0 to about $90 \%$ when the applied potentials increased from 0 to $0.65 \mathrm{~V}$ vs. $\mathrm{Ag} / \mathrm{AgCl}$. Hence, $\mathrm{S}^{0}$ was the main intermediate sulfur containing species on the bornite surface during the oxidation process and the production of $\mathrm{S}^{0}$ can be enhanced with the increase of applied potentials. In addition, no significant amount of insoluble sulfate $\left(\mathrm{SO}_{4}{ }^{2-}\right)$ formed on the bornite surface in $0.3-0.65 \mathrm{~V}$ vs. $\mathrm{Ag} / \mathrm{AgCl}$.

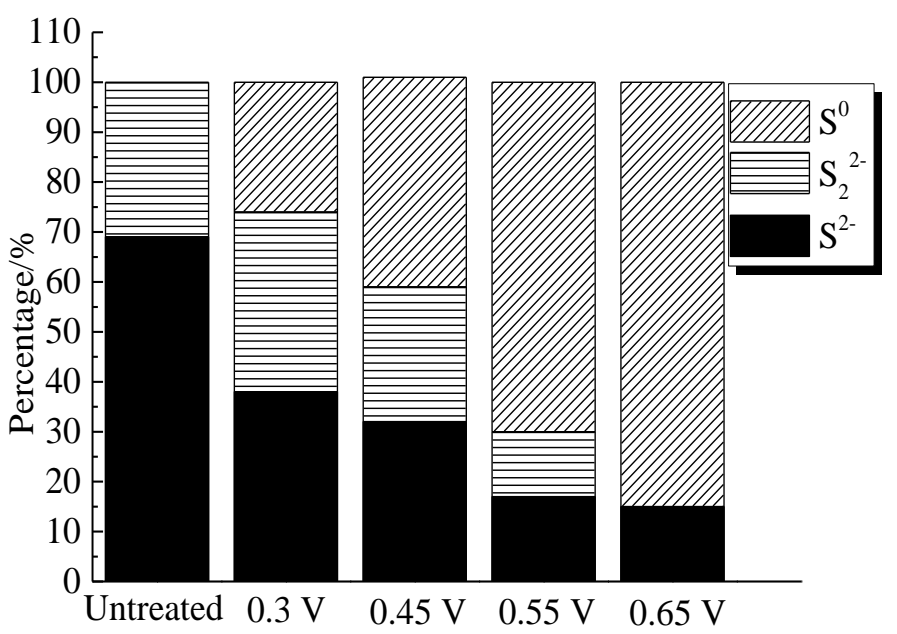

Figure 14. Distribution of sulfur containing species on bornite surface after treating by different potential of $0,0.3,0.45,0.55,0.65 \mathrm{~V}$, respectively (Implemented on the model of ESCALAB 250Xi of Al $\mathrm{K} \alpha \mathrm{X}$-ray source with $20 \mathrm{eV}$ constant pass energy and $0.1 \mathrm{eV} /$ step; Fitted by Thermo Avantage 5.52, C $1 \mathrm{~s} 284.8 \mathrm{eV}$ as reference, Shirley method, Gaussian-Lorentzian function).

The XPS spectra of the $\mathrm{O} 1 \mathrm{~s}$ peaks of the bornite surface after treatment with different potentials are shown in Figure 15. The binding energy of $\mathrm{O} 1 \mathrm{~s}$ at $529.6 \pm 0.1 \mathrm{eV}, 531.5 \pm 0.1 \mathrm{eV}$ and $532.8 \pm 0.1 \mathrm{eV}$ can be mainly attributed to $\mathrm{O}^{2-}$ in oxide phases, $\mathrm{OH}^{-}$in hydroxide species and oxygen in sulfate or/and water, respectively [36]. It can be found that $\mathrm{O}^{2-}$ and $\mathrm{OH}^{-}$were the main oxygen containing species on bornite surface after treating at $0.3 \mathrm{~V} \mathrm{vs} . \mathrm{Ag} / \mathrm{AgCl}$, and sulfate or/and water formed at a higher potential. The percentage of oxygen containing species on bornite surface after treating by 
different potentials calculated from the peak area is shown in Figure 16. The percentages of $\mathrm{O}^{2-}$ decreased significantly with the increase of applied potential, but the proportion of $\mathrm{OH}^{-}$increased with the increase of applied potential. This was consistent with the conclusion that the percentage of $\mathrm{FeOOH}$ in iron containing species increased with the increase of applied potentials from analyzing the Fe 3p peaks.
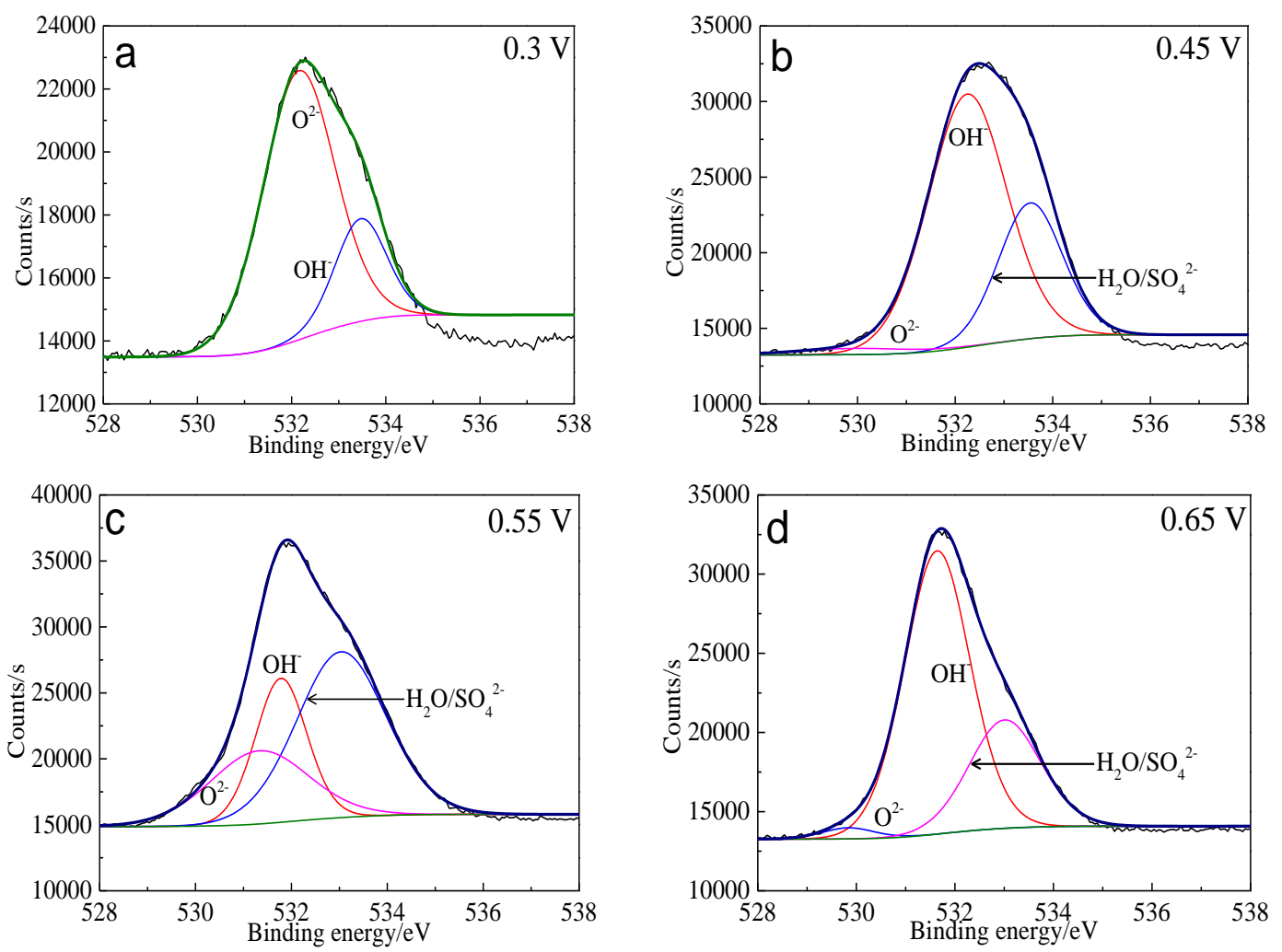

Figure 15. XPS spectra of $\mathrm{O} 1 \mathrm{~s}$ peaks of bornite surface after treating by different potential of $0,0.3$, 0.45, 0.55, $0.65 \mathrm{~V}$, respectively: (a) $0.3 \mathrm{~V}$; (b) $0.45 \mathrm{~V}$; (c) $0.55 \mathrm{~V}$; (d) $0.65 \mathrm{~V}$ (Implemented on the model of ESCALAB 250Xi of Al K $\alpha$ X-ray source with $20 \mathrm{eV}$ constant pass energy and $0.1 \mathrm{eV} /$ step; Fitted by Thermo Avantage 5.52, C 1s $284.8 \mathrm{eV}$ as reference, Shirley method, Gaussian-Lorentzian function).

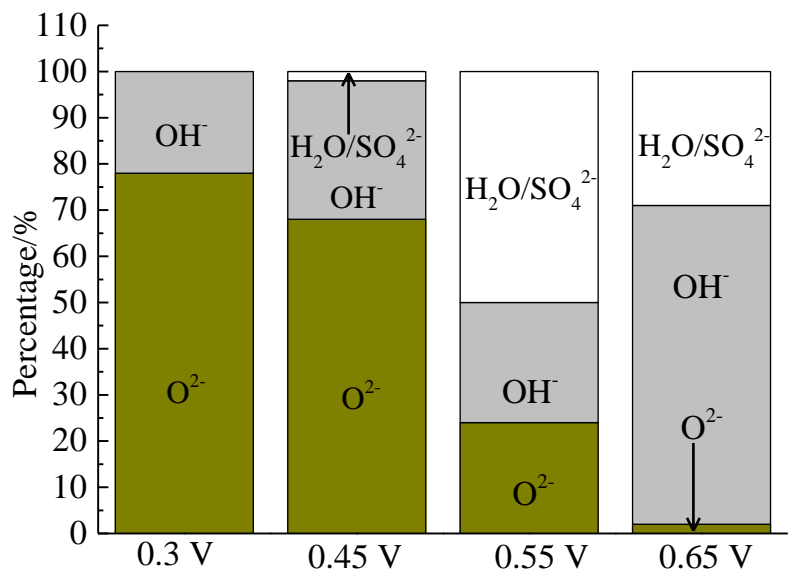

Figure 16. Distribution of oxygen containing species on bornite surface after treating by different potential of $0,0.3,0.45,0.55,0.65 \mathrm{~V}$, respectively (Implemented on the model of ESCALAB 250Xi of Al $\mathrm{K} \alpha \mathrm{X}$-ray source with $20 \mathrm{eV}$ constant pass energy and $0.1 \mathrm{eV} /$ step; Fitted by Thermo Avantage 5.52, C $1 \mathrm{~s} 284.8 \mathrm{eV}$ as reference, Shirley method, Gaussian-Lorentzian function). 


\subsection{Intermediate Species of Bornite Surface during Bioleaching}

Bioleaching of bornite by A. caldus, L. ferriphilum and mixed culture was conducted. The variation of copper extraction and redox potential is presented in Figure 17. The redox potential during bornite bioleaching in the presence of mixed culture was higher than that in the presence of single strains of A. caldus and L. ferriphilum. Accordingly, the copper extraction of bornite bioleaching in the presence of mixed culture was also higher than that in the presence of single strains of A. caldus and L. ferriphilum. Redox potential during bornite bioleaching was in the range of $0.25-0.65 \mathrm{~V}$ vs. $\mathrm{Ag} / \mathrm{AgCl}$ where bornite was mainly directly oxidized, and a high redox potential was beneficial for accelerating the oxidative dissolution of bornite. This was different with chalcopyrite bioleaching which can be accelerated at relatively low redox potential and passivated at high redox potential [46-48].
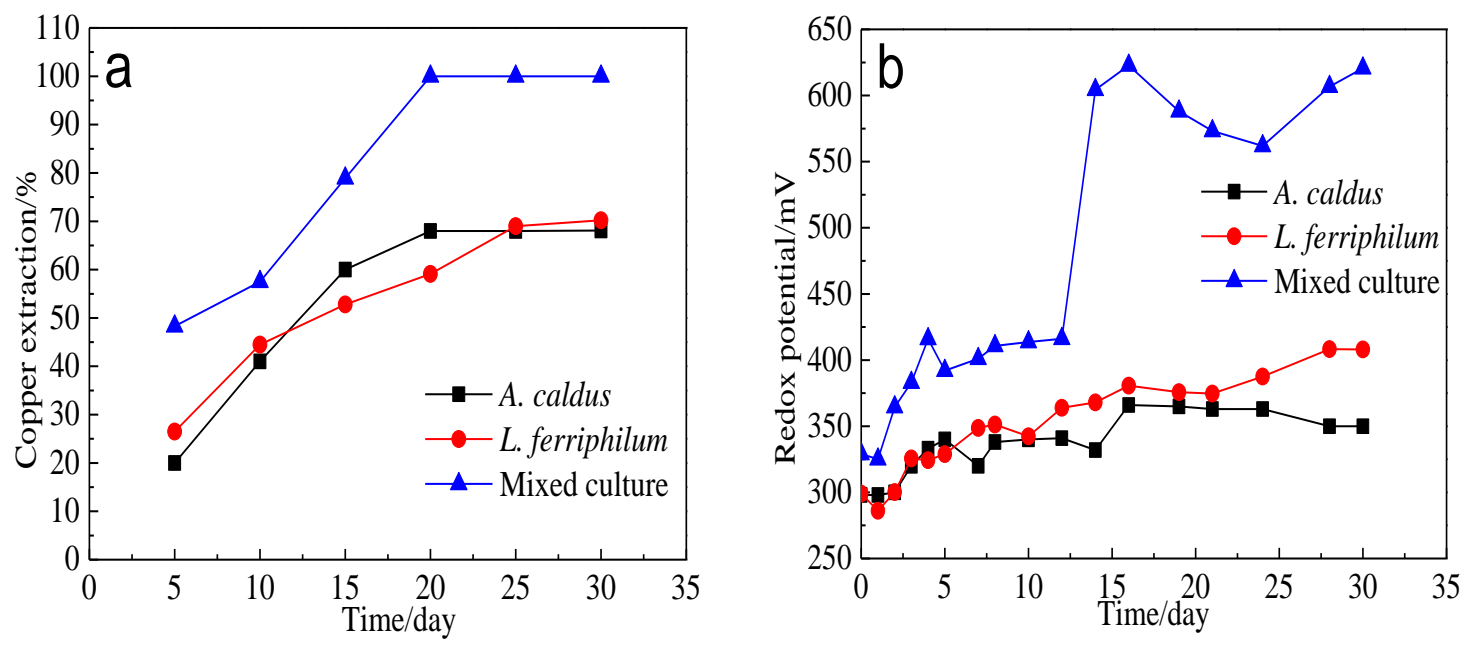

Figure 17. Bioleaching of bornite by A. caldus, L. ferriphilum and mixed culture consisting of A. caldus and L. ferriphilum: (a) Copper extraction; (b) Redox potential.

XPS spectra of $\mathrm{Cu} 2 \mathrm{p}$ peaks and $\mathrm{Cu}$ LMM peaks of bornite leached by different microorganisms for different numbers of days are shown in Figure 18.
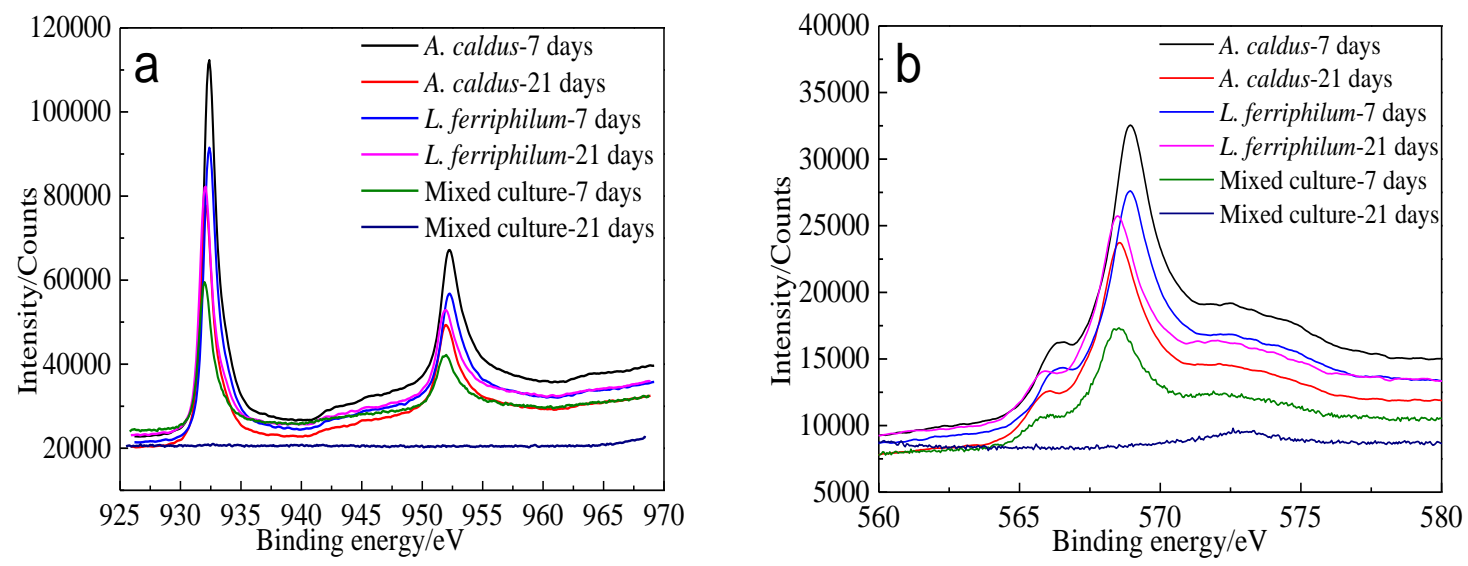

Figure 18. XPS spectra of $\mathrm{Cu}$ peaks of bornite surface leached by A. caldus, L. ferriphilum and mixed culture consisting of $A$. caldus and L. ferriphilum for 7 and 21 days, respectively (Implemented on the model of ESCALAB 250Xi of Al K $\alpha$ X-ray source with $20 \mathrm{eV}$ constant pass energy and $0.1 \mathrm{eV} /$ step; Fitted by Thermo Avantage 5.52, C 1s $284.8 \mathrm{eV}$ as reference, Shirley method, Gaussian-Lorentzian function): (a) $\mathrm{Cu} 2 \mathrm{p}$ peak; (b) Cu LMM peak. 
$\mathrm{Cu} 2 \mathrm{p}_{3 / 2}$ peaks of leached bornite samples were all centered at about $932.0-932.5 \mathrm{eV}$, and the $\mathrm{Cu} \mathrm{LMM}$ peaks were all centered at about $568.0-568.7 \mathrm{eV}$, indicating that $\mathrm{CuS}$ should be the main intermediate copper containing species during bornite bioleaching [38,39]. The $S 2 p$ peaks were fitted (Figure 19) and the $S 2 p_{3 / 2}$ values of binding energy and full width at half maximum (FWHM) are presented in Table 6.
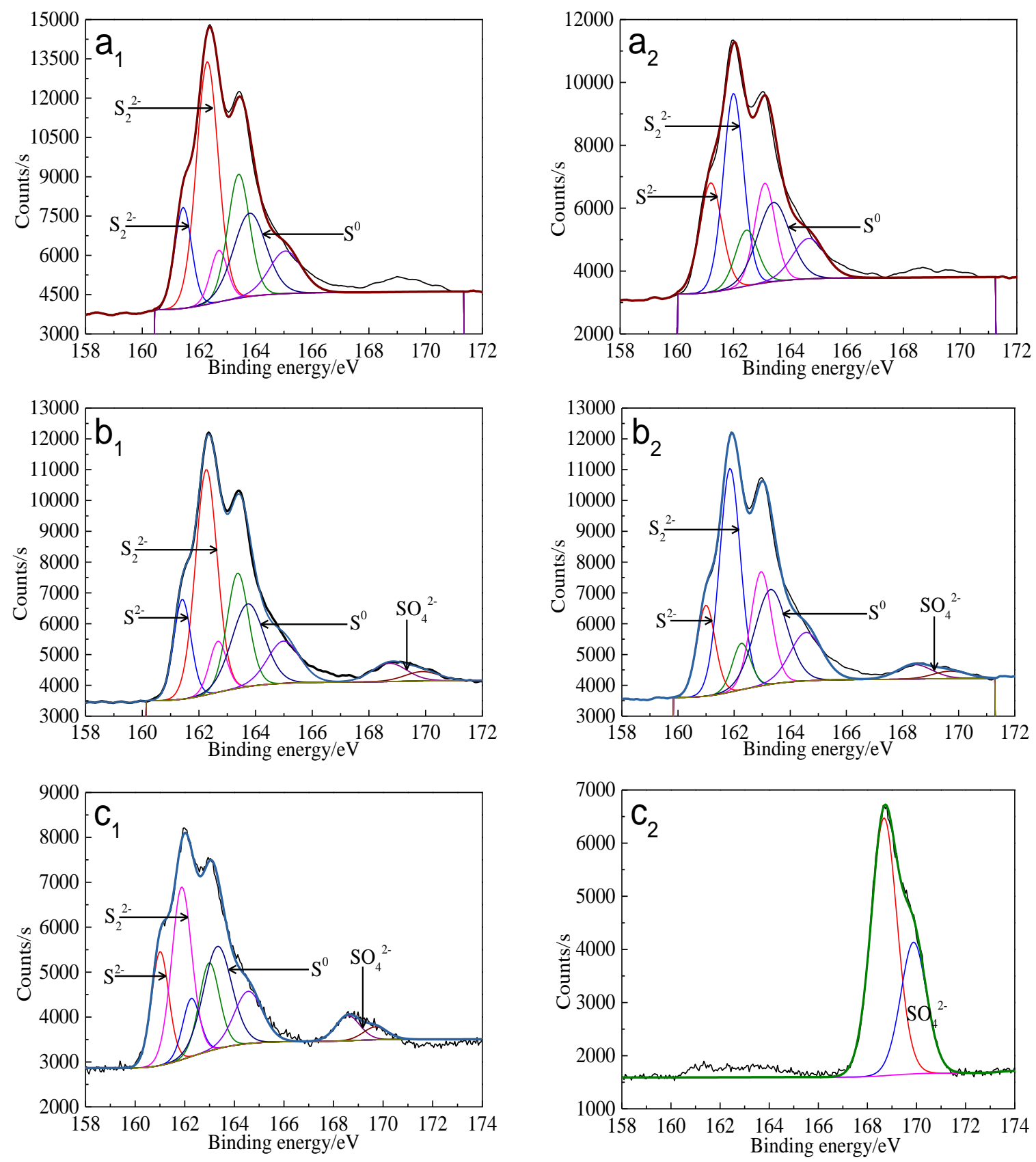

Figure 19. XPS spectra of $S 2 p$ peaks of bornite surface leached by A. caldus, L. ferriphilum and mixed culture consisting of $A$. caldus and L. ferriphilum for 7 and 21 days, respectively (Implemented on the model of ESCALAB 250Xi of Al K $\alpha$ X-ray source with $20 \mathrm{eV}$ constant pass energy and $0.1 \mathrm{eV} / \mathrm{step}$; Fitted by Thermo Avantage 5.52, C 1s $284.8 \mathrm{eV}$ as reference, Shirley method, Gaussian-Lorentzian function): $\left(\mathbf{a}_{1}\right)$-A. caldus and 7 days; $\left(\mathbf{a}_{2}\right)$-A. caldus and 21 days; $\left(\mathbf{b}_{\mathbf{1}}\right)$-L. ferriphilum and 7 days; $\left(\mathbf{b}_{\mathbf{2}}\right)$-L. ferriphilum and 21 days; $\left(\mathbf{c}_{1}\right)$-mixed culture and 7 days; ( $\left.\mathbf{c}_{2}\right)$-mixed culture and 21 days. 
Table 6. Binding energy and FWHM value for XPS spectra of $S 2 p_{3 / 2}$ peaks of bornite leached by $A$. caldus, L. ferriphilum and mixed culture consisting of A. caldus and L. ferriphilum for 7 and 21 days, respectively (Implemented on the model of ESCALAB 250Xi of Al $\mathrm{K}_{\alpha} \mathrm{X}$-ray source with $20 \mathrm{eV}$ constant pass energy and $0.1 \mathrm{eV}$ /step; Fitted by Thermo Avantage 5.52, C 1s $284.8 \mathrm{eV}$ as reference, Shirley method, Gaussian-Lorentzian function) (FWHM means full width at half maximum, B.E. means binding energy).

\begin{tabular}{cccccccccc}
\hline \multirow{2}{*}{ Conditions } & Time & \multicolumn{2}{c}{ Peak 1 } & \multicolumn{2}{c}{ Peak 2 } & \multicolumn{2}{c}{ Peak 3 } & \multicolumn{2}{c}{ Peak 4 } \\
\cline { 2 - 10 } & /days & $\begin{array}{c}\text { B.E. } \\
\mathbf{( e V )}\end{array}$ & $\begin{array}{c}\text { FWHM } \\
\mathbf{( e V )}\end{array}$ & $\begin{array}{c}\text { B.E. } \\
\mathbf{( e V )}\end{array}$ & $\begin{array}{c}\text { FWHM } \\
\mathbf{( e V )}\end{array}$ & $\begin{array}{c}\text { B.E. } \\
\mathbf{( e V )}\end{array}$ & $\begin{array}{c}\text { FWHM } \\
(\mathbf{e V})\end{array}$ & $\begin{array}{c}\text { B.E. } \\
\mathbf{( e V )}\end{array}$ & $\begin{array}{c}\text { FWHM } \\
(\mathbf{e V})\end{array}$ \\
\hline \multirow{2}{*}{ A. caldus } & 7 & 161.4 & 0.7 & 162.3 & 0.9 & 163.8 & 1.4 & - & - \\
& 21 & 161.2 & 0.9 & 162.1 & 0.8 & 163.5 & 1.4 & - & - \\
\hline \multirow{2}{*}{ L. ferriphilum } & 7 & 161.4 & 0.7 & 162.3 & 0.9 & 163.7 & 1.4 & - & - \\
& 21 & 161.0 & 0.7 & 162.0 & 0.9 & 163.4 & 1.4 & 168.4 & 1.5 \\
\hline \multirow{2}{*}{ Mixed culture } & 7 & 161.1 & 0.8 & 162.0 & 0.9 & 163.1 & 1.0 & 168.5 & 1.1 \\
& 21 & - & - & - & - & - & - & 168.6 & 1.3 \\
\hline
\end{tabular}

$\mathrm{S}^{2-}, \mathrm{S}_{2}{ }^{2-}$ and $\mathrm{S}^{0}$ were the main intermediate sulfur containing species on bornite surface during bioleaching by $A$. caldus. Except for $\mathrm{S}^{2-}, \mathrm{S}_{2}{ }^{2-}$ and $\mathrm{S}^{0}, \mathrm{SO}_{4}{ }^{2-}$ was detected as the main intermediate species on bornite surface during bioleaching by L. ferriphilum and by mixed culture. The distribution of sulfur-containing species on the bornite surface leached by different microorganisms for different days was calculated as shown in Figure 20. The proportions of $\mathrm{S}^{2-}, \mathrm{S}_{2}{ }^{2-}$ and $\mathrm{S}^{0}$ on bornite surface changed slightly during bioleaching by $A$. caldus, and the percentage of $\mathrm{S}^{0}$ kept around $28 \%$. The percentages of sulfur containing species on the bornite surface during bioleaching by L. ferriphilum changed slightly and about $5 \% \mathrm{SO}_{4}{ }^{2-}$ formed on the bornite surface. Particularly, the distributions of sulfur containing species on the bornite surface varied significantly during bioleaching by mixed culture and $\mathrm{SO}_{4}{ }^{2-}$ was the predominant sulfur containing species on the bornite surface at the end of bioleaching. Hence, the oxidative dissolution of bornite can be significantly accelerated at high redox potential, which was one important reason why mixed culture was more effective than single strains of $A$. caldus and L. ferriphilum.

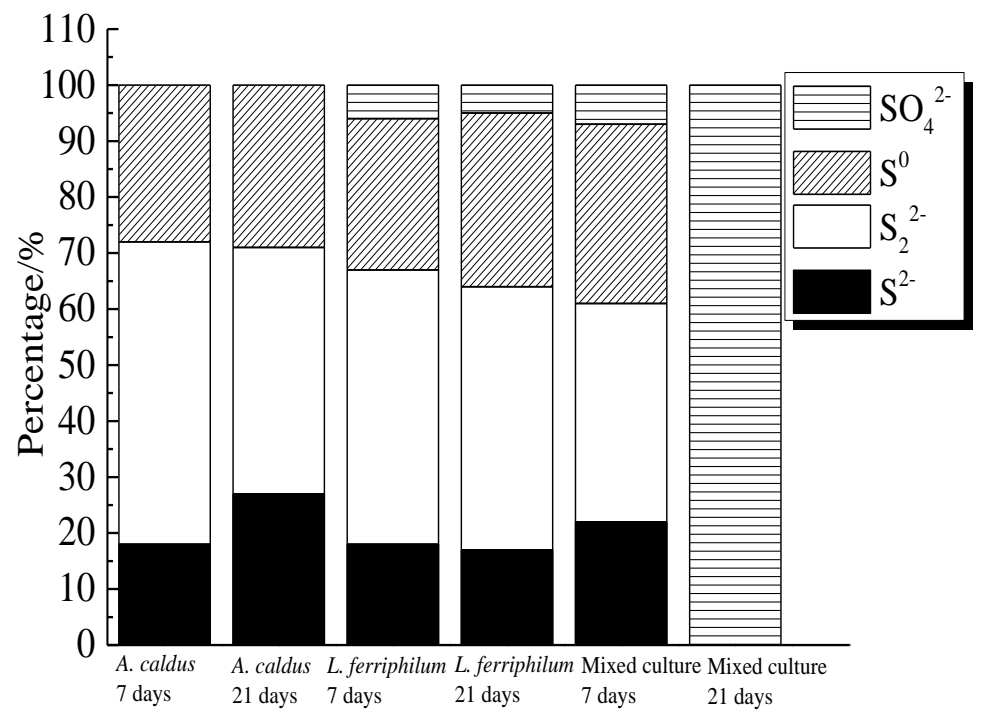

Figure 20. Distribution of sulfur containing species on bornite surface leached by A. caldus, L. ferriphilum and mixed culture consisting of $A$. caldus and L. ferriphilum for 7 and 21 days, respectively (Implemented on the model of ESCALAB 250Xi of $\mathrm{Al} \mathrm{K} \alpha$ X-ray source with $20 \mathrm{eV}$ constant pass energy and $0.1 \mathrm{eV} /$ step; Fitted by Thermo Avantage 5.52, C 1s $284.8 \mathrm{eV}$ as reference, Shirley method, Gaussian-Lorentzian function). 


\subsection{The Proposed Model for Interpreting the Dissolution Process of Bornite during Bioleaching}

The proposed model for interpreting the dissolution process of bornite during bioleaching is provided in Figure 21. Bornite is a conductor with high metallic conductivity. The $\mathrm{E}_{\text {redox }}$ of redox couple of $\mathrm{Fe}^{3+} / \mathrm{Fe}^{2+}$ was located below the Fermi energy, so bornite can transfer electrons to the $\mathrm{Fe}^{3+} / \mathrm{Fe}^{2+}$ couple and be oxidized. The $\mathrm{E}_{\text {redox }}$ of redox couple of $\mathrm{O}_{2} / \mathrm{H}_{2} \mathrm{O}$ was always situated below the Fermi energy and in the range of valence band, but the content of dissolved $\mathrm{O}_{2}$ was extremely low at normal pressure, that was why redox potential in bioleaching system was mainly determined by $\mathrm{Fe}^{3+} / \mathrm{Fe}^{2+}$ couple [46,49]. Bornite tended to be directly oxidized to $\mathrm{CuS}, \mathrm{FeOOH}$ and $\mathrm{S}^{0}$ on the surface, $\mathrm{H}_{2} \mathrm{~S}$ and $\mathrm{Fe}^{2+}$ in the solution at potential of higher than $0.3 \mathrm{~V}$ vs. $\mathrm{Ag} / \mathrm{AgCl}$. The production of $\mathrm{S}^{0}$ and $\mathrm{FeOOH}$ on bornite surface can be significantly accelerated with the increase of redox potential but the formed elemental sulfur did not further oxidize to insoluble sulfate. $\mathrm{H}_{2} \mathrm{~S}$ can be further oxidized to $\mathrm{SO}_{4}{ }^{2-}$ through series of intermediate species, and $\mathrm{Fe}^{2+}$ can be oxidized to $\mathrm{Fe}^{3+}$ by microorganisms. The redox couple of $\mathrm{Fe}^{3+} / \mathrm{Fe}^{2+}$ acted as the main oxidant in directly oxidizing bornite, and insoluble sulfate of jarosite can be produced through the chemical reaction of $\mathrm{Fe}^{3+}, \mathrm{SO}_{4}{ }^{2-}, \mathrm{H}_{2} \mathrm{O}$ and $\mathrm{M}^{+}$in solution as shown in Equation (9), where $\mathrm{M}$ is a monovalent cation, such as $\mathrm{H}_{3} \mathrm{O}^{+}, \mathrm{Na}^{+}, \mathrm{K}^{+}$and $\mathrm{NH}_{4}{ }^{+}$:

$$
\mathrm{M}^{+}+3 \mathrm{Fe}^{3+}+2 \mathrm{SO}_{4}{ }^{2-}+6 \mathrm{H}_{2} \mathrm{O} \rightarrow \mathrm{MFe}_{3}\left(\mathrm{SO}_{4}\right)_{2}(\mathrm{OH})_{6}+6 \mathrm{H}^{+}
$$

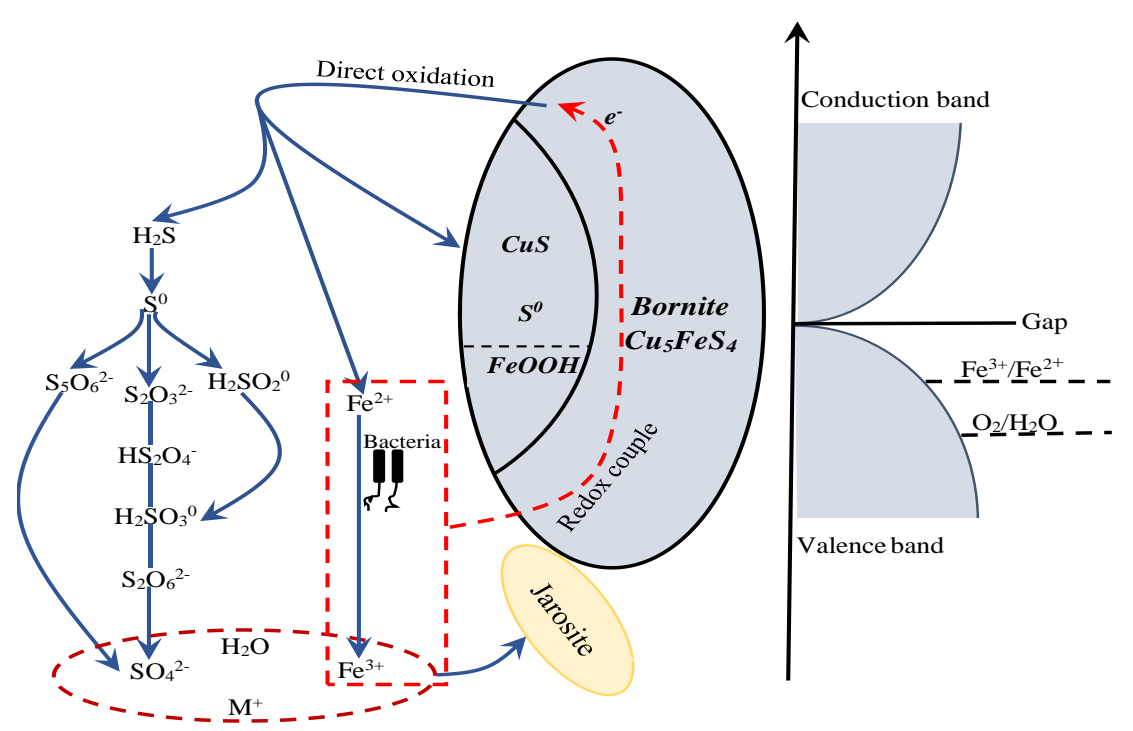

Figure 21. The proposed model for interpreting the dissolution process of bornite in bioleaching by moderately thermophilic microorganisms.

\section{Conclusions}

Bornite with formula of $\left(\mathrm{Cu}^{+}\right)_{5} \mathrm{Fe}^{3+}\left(\mathrm{S}^{2-}\right)$ is a conductor with metallic conductivity whose behavior was similar to that of metals. The existence of the electrical conductivity was mainly due to the $3 \mathrm{~d}$ orbitals of Fe atoms crossed over the Fermi level and interacting with the high-level orbitals of $\mathrm{Cu}$ atoms, thus making Fe atoms the most active species in the bornite unit cell. After reconstruction of (001)-S surface, the inner core $\mathrm{Cu}$ atoms were exposed, making them easily react with chemicals. The shortening of the Fe-S bond enhanced the Fe-S bond covalence, reducing the reaction activity of the Fe atoms. The inner $\mathrm{Cu}$ atoms were exposed to the surface after relaxation, which increased the electron density on the surface and facilitated the reaction between reactant and the bornite (111)-S surface. Tighter bonding occurred between the inner Fe atoms and the surface $S$ atoms. Thus, the corresponding Fe-S bonds were relatively hard to break. Therefore, during the initial stages of chemical reactions on 
the (111)-S surface, the inner irons can hardly participate. The $\mathrm{Cu}$ and $\mathrm{S}$ atoms were oxidized while the Fe atoms were reduced in surface reconstruction.

Bornite tended to be directly oxidized to $\mathrm{CuS}, \mathrm{FeOOH}$ and $\mathrm{S}^{0}$ on the surface, $\mathrm{H}_{2} \mathrm{~S}$ and $\mathrm{Fe}^{2+}$ in the solution at potential of higher than $0.3 \mathrm{~V}$ vs. $\mathrm{Ag} / \mathrm{AgCl}$. The redox couple of $\mathrm{Fe}^{3+} / \mathrm{Fe}^{2+}$ acted as the main oxidant in directly oxidizing bornite. $\mathrm{H}_{2} \mathrm{~S}$ can be further oxidized to $\mathrm{SO}_{4}{ }^{2-}$ through series of intermediate species. The formed elemental sulfur on bornite surface did not further oxidize to insoluble sulfate which can be produced through the chemical reaction of $\mathrm{Fe}^{3+}, \mathrm{SO}_{4}{ }^{2-}, \mathrm{H}_{2} \mathrm{O}$ and $\mathrm{M}^{+}$ in solution. High redox potential was beneficial for the oxidative dissolution of bornite, which was one important reason why mixed culture was more effective than single strains of $A$. caldus and L. ferriphilum. This work can help to improve the bioleaching kinetics of bornite and chalcopyrite as well as help to elucidate the biomineralization of $\mathrm{Cu}$-sulfides and the geo-biological-chemical circulation on the Earth.

Acknowledgments: This work was supported by the National Natural Science Foundation of China (project No. 51704331, 51774332 and 51374248), Young Elite Scientists Sponsorship Program by CAST (2017QNRC001) and Innovation-Driven Project of Central South University (2018CX019).

Author Contributions: Hongbo Zhao conceived and designed the experiments; Xiaotao Huang, Minghao Hu, Yisheng Zhang and Hongbo Zhao performed the experiments; Hongbo Zhao, Minghao Hu and Chenyang Zhang analyzed the data; Jun Wang, Wenqing Qin and Guanzhou Qiu contributed reagents/materials/analysis tools; Hongbo Zhao wrote the paper.

Conflicts of Interest: The authors declare no conflict of interest. The Funding sponsors had no role in the design of the study; in the collection, analyses, or interpretation of data; in the writing of the manuscript, and in the decision to publish the results.

\section{References}

1. Brierley, C.L. Biohydrometallurgical prospects. Hydrometallurgy 2010, 104, 324-328. [CrossRef]

2. Liu, H.; Xia, J.; Nie, Z.; Ma, C.; Zheng, L.; Hong, C.; Zhao, Y.; Wen, W. Bioleaching of chalcopyrite by acidianus manzaensis under different constant pH. Miner. Eng. 2016, 98, 80-89. [CrossRef]

3. Liu, H.C.; Xia, J.L.; Nie, Z.Y. Relatedness of $\mathrm{Cu}$ and Fe speciation to chalcopyrite bioleaching by Acidithiobacillus ferrooxidans. Hydrometallurgy 2015, 156, 40-46. [CrossRef]

4. Majuste, D.; Ciminelli, V.S.T.; Osseo-Asare, K.; Dantas, M.S.S.; Magalhães-Paniago, R. Electrochemical dissolution of chalcopyrite: Detection of bornite by synchrotron small angle X-ray diffraction and its correlation with the hindered dissolution process. Hydrometallurgy 2012, 111-112, 114-123. [CrossRef]

5. Pesic, B.; Olson, F.A. Dissolution of bornite in sulfuric acid using oxygen as oxidant. Hydrometallurgy 1984, 12, 195-215. [CrossRef]

6. Zhao, H.; Wang, J.; Hu, M.; Qin, W.; Zhang, Y.; Qiu, G. Synergistic bioleaching of chalcopyrite and bornite in the presence of Acidithiobacillus ferrooxidans. Bioresour. Technol. 2013, 149, 71-76. [CrossRef] [PubMed]

7. Zhao, H.; Wang, J.; Gan, X.; Zheng, X.; Tao, L.; Hu, M.; Li, Y.; Qin, W.; Qiu, G. Effects of pyrite and bornite on bioleaching of two different types of chalcopyrite in the presence of Leptospirillum ferriphilum. Bioresour. Technol. 2015, 194, 28-35. [CrossRef] [PubMed]

8. Acres, R.G.; Harmer, S.L.; Beattie, D.A. Synchrotron XPS studies of solution exposed chalcopyrite, bornite, and heterogeneous chalcopyrite with bornite. Int. J. Miner. Proc. 2010, 94, 43-51. [CrossRef]

9. Price, D.C.; Chilton, J.P. The anodic reactions of bornite in sulphuric acid solution. Hydrometallurgy 1981, 7, 117-133. [CrossRef]

10. Price, D.C.; Chilton, J.P. The electroleaching of bornite and chalcopyrite. Hydrometallurgy 1980, 5, 381-394. [CrossRef]

11. Safarzadeh, M.S.; Li, J.; Moats, M.S.; Miller, J.D. The stability of selected sulfide minerals in sulfuric acid and acidic thiocyanate solutions. Electrochim. Acta 2012, 78, 133-138. [CrossRef]

12. Bevilaqua, D.; Garcia, O., Jr.; Tuovinen, O.H. Oxidative dissolution of bornite by Acidithiobacillus ferrooxidans. Process Biochem. 2010, 45, 101-106. [CrossRef]

13. Qin, W.Q.; Wang, J.; Zhang, Y.S.; Zhen, S.J.; Shang, H.; Liu, Q.; Shi, H.B.; Zhang, J.W.; Qiu, G.Z. Electrochemical behavior of massive bornite bioleached electrodes in the presence of Acidithiobacillus ferrooxidans and Acidithiobacillus caldus. Adv. Mater. Res. 2009, 71-73, 417-420. [CrossRef] 
14. Bevilaqua, D.; Acciari, H.A.; Benedetti, A.V.; Fugivara, C.S.; Filho, G.T.; Garcia, O., Jr. Electrochemical noise analysis of bioleaching of bornite $\left(\mathrm{Cu}_{5} \mathrm{FeS}_{4}\right)$ by Acidithiobacillus ferrooxidans. Hydrometallurgy 2006, 83, 50-54. [CrossRef]

15. Bevilaqua, D.; Acciari, H.A.; Arena, F.A.; Benedetti, A.V.; Fugivara, C.S.; Filho, G.T.; Garcia, O., Jr. Utilization of electrochemical impedance spectroscopy for monitoring bornite $\left(\mathrm{Cu}_{5} \mathrm{FeS}_{4}\right)$ oxidation by Acidithiobacillus ferrooxidans. Miner. Eng. 2009, 22, 254-262. [CrossRef]

16. Watling, H. The bioleaching of sulphide minerals with emphasis on copper sulphides-A review. Hydrometallurgy 2006, 84, 81-108. [CrossRef]

17. Rohwerder, T.; Gehrke, T.; Kinzler, K.; Sand, W. Bioleaching review part A. Appl. Microbiol. Biotechnol. 2003, 63, 239-248. [CrossRef] [PubMed]

18. Olson, G.; Brierley, J.; Brierley, C. Bioleaching review part B. Appl. Microbiol. Biotechnol. 2003, 63, $249-257$. [CrossRef] [PubMed]

19. Oliveira, C.D.; Lima, G.F.D.; Abreu, H.A.D.; Duarte, H.A. Reconstruction of the chalcopyrite surfacesA DFT study. J. Phys. Chem. C 2012, 116, 6357-6366. [CrossRef]

20. Oliveira, C.D.; Duarte, H.A. Disulphide and metal sulphide formation on the reconstructed $\left(\begin{array}{lll}0 & 0 & 1\end{array}\right)$ surface of chalcopyrite: A DFT study. Appl. Surf. Sci. 2010, 257, 1319-1324. [CrossRef]

21. Anisimov, V.I.; Zaanen, J.; Andersen, O.K. Band theory and mott insulators: Hubbard U instead of stoner I. Phys. Rev. B 1991, 44, 943. [CrossRef] [PubMed]

22. Pickett, W.E.; Erwin, S.C.; Ethridge, E.C. Reformulation of the LDA+ U method for a local orbital basis. Physics 1998, 58, 1201-1209.

23. Anisimov, V.I. First-principles calculations of the electronic structure and spectra of strongly correlated systems: LDA+ U method. J. Phys. Condens. Matter 2006, 9, 767-808. [CrossRef]

24. Ding, Y.; Veblen, D.R.; Prewitt, C.T. Possible Fe/Cu ordering schemes in the 2a superstructure of bornite $\left(\mathrm{Cu}_{5} \mathrm{FeS}_{4}\right)$. Am. Miner. 2005, 90, 1265-1269. [CrossRef]

25. Shirley, D.A. High-resolution X-ray photoemission spectrum of the valence bands of gold. Phys. Rev. B 1972, 5, 4709. [CrossRef]

26. Arce, E.M.; González, I. A comparative study of electrochemical behavior of chalcopyrite, chalcocite and bornite in sulfuric acid solution. Int. J. Miner. Process. 2002, 67, 17-28. [CrossRef]

27. Sauber, M.; Dixon, D.G. Electrochemical study of leached chalcopyrite using solid paraffin-based carbon paste electrodes. Hydrometallurgy 2011, 110, 1-12. [CrossRef]

28. Mikhlin, Y.L.; Tomashevich, Y.V.; Asanov, I.P.; Okotrub, A.V.; Varnek, V.A.; Vyalikh, D.V. Spectroscopic and electrochemical characterization of the surface layers of chalcopyrite $\left(\mathrm{CuFeS}_{2}\right)$ reacted in acidic solutions. Appl. Surf. Sci. 2004, 225, 395-409. [CrossRef]

29. Yin, Q.; Kelsall, G.H.; Vaughan, D.J.; England, K.E.R. Atmospheric and electrochemical oxidation of the surface of chalcopyrite $\left(\mathrm{CuFeS}_{2}\right)$. Geochim. Et Cosmochim. Acta 1995, 59, 1091-1100. [CrossRef]

30. Elsherief, A.E. The influence of cathodic reduction, $\mathrm{Fe}^{2+}$ and $\mathrm{Cu}^{2+}$ ions on the electrochemical dissolution of chalcopyrite in acidic solution. Miner. Eng. 2002, 15, 215-223. [CrossRef]

31. Gu, G.; Hu, K.; Zhang, X.; Xiong, X.; Yang, H. The stepwise dissolution of chalcopyrite bioleached by Leptospirillum ferriphilum. Electrochim. Acta 2013, 103, 50-57. [CrossRef]

32. Gómez, C.; Figueroa, M.; Muñoz, J.; Blázquez, M.L.; Ballester, A. Electrochemistry of chalcopyrite. Hydrometallurgy 1996, 43, 331-344. [CrossRef]

33. Liang, C.L.; Xia, J.L.; Yang, Y.; Nie, Z.Y.; Zhao, X.J.; Zheng, L.; Ma, C.Y.; Zhao, Y.D. Characterization of the thermo-reduction process of chalcopyrite at $65^{\circ} \mathrm{C}$ by cyclic voltammetry and XANES spectroscopy. Hydrometallurgy 2011, 107, 13-21. [CrossRef]

34. Wang, J.; Liao, R.; Tao, L.; Zhao, H.; Zhai, R.; Qin, W.; Qiu, G. A comprehensive utilization of silver-bearing solid wastes in chalcopyrite bioleaching. Hydrometallurgy 2017, 169, 152-157. [CrossRef]

35. Zhao, H.; Wang, J.; Gan, X.; Hu, M.; Zhang, E.; Qin, W.; Qiu, G. Cooperative bioleaching of chalcopyrite and silver-bearing tailing by mixed moderately thermophilic culture: An emphasis on the chalcopyrite dissolution with XPS and electrochemical analysis. Miner. Eng. 2015, 81, 29-39. [CrossRef]

36. Ghahremaninezhad, A.; Dixon, D.G.; Asselin, E. Electrochemical and XPS analysis of chalcopyrite $\left(\mathrm{CuFeS}_{2}\right)$ dissolution in sulfuric acid solution. Electrochim. Acta 2013, 87, 97-112. [CrossRef]

37. Harmer, S.L.; Pratt, A.R.; Nesbitt, H.W.; Fleet, M.E. Reconstruction of fracture surfaces on bornite. Can. Miner. 2005, 43, 1619-1630. [CrossRef] 
38. Nakai, I.; Sugitani, Y.; Nagashima, K.; Niwa, Y. X-ray photoelectron spectroscopic study of copper minerals. J. Inorg. Nucl. Chem. 1976, 40, 789-791. [CrossRef]

39. Živković, Ž.D.; Mitevska, N.; Savović, V. Kinetics and mechanism of the chalcopyrite-pyrite concentrate oxidation process. Thermochim. Acta 1996, 282-283, 121-130. [CrossRef]

40. Descostes, M.; Mercier, F.; Thromat, N.; Beaucaire, C.; Gautier-Soyer, M. Use of XPS in the determination of chemical environment and oxidation state of iron and sulfur samples: Constitution of a data basis in binding energies for Fe and $\mathrm{S}$ reference compounds and applications to the evidence of surface species of an oxidized pyrite in a carbonate medium. Appl. Surf. Sci. 2000, 165, 288-302.

41. Harmer, S.L.; Thomas, J.E.; Fornasiero, D.; Gerson, A.R. The evolution of surface layers formed during chalcopyrite leaching. Geochim. Cosmochim. Acta 2006, 70, 4392-4402. [CrossRef]

42. Buckley, A.N.; Woods, R. An X-ray photoelectron spectroscopic study of the oxidation of chalcopyrite. Australian J. Chem. 1984, 37, 2403-2413. [CrossRef]

43. Klauber, C.; Parker, A.; van Bronswijk, W.; Watling, H. Sulphur speciation of leached chalcopyrite surfaces as determined by X-ray photoelectron spectroscopy. Int. J. Miner. Process. 2001, 62, 65-94. [CrossRef]

44. Li, Y.; Kawashima, N.; Li, J.; Chandra, A.P.; Gerson, A.R. A review of the structure, and fundamental mechanisms and kinetics of the leaching of chalcopyrite. Adv. Coll. Interface Sci. 2013, 197, 1-32. [CrossRef] [PubMed]

45. Zhao, H.; Gan, X.; Wang, J.; Tao, L.; Qin, W.; Qiu, G. Stepwise bioleaching of Cu-Zn mixed ores with comprehensive utilization of silver-bearing solid waste through a new technique process. Hydrometallurgy 2017, 171, 374-386. [CrossRef]

46. Zhao, H.; Wang, J.; Yang, C.; Hu, M.; Gan, X.; Tao, L.; Qin, W.; Qiu, G. Effect of redox potential on bioleaching of chalcopyrite by moderately thermophilic bacteria: An emphasis on solution compositions. Hydrometallurgy 2015, 151, 141-150. [CrossRef]

47. Wang, J.; Gan, X.; Zhao, H.; Hu, M.; Li, K.; Qin, W.; Qiu, G. Dissolution and passivation mechanisms of chalcopyrite during bioleaching: DFT calculation, XPS and electrochemistry analysis. Miner. Eng. 2016, 98, 264-278. [CrossRef]

48. Zhao, H.; Huang, X.; Wang, J.; Li, Y.; Liao, R.; Wang, X.; Qiu, X.; Xiong, Y.; Qin, W.; Qiu, G. Comparison of bioleaching and dissolution process of p-type and n-type chalcopyrite. Miner. Eng. 2017, 109, 153-161. [CrossRef]

49. Zhao, H.; Wang, J.; Tao, L.; Cao, P.; Yang, C.; Qin, W.; Qiu, G. Roles of oxidants and reductants in bioleaching system of chalcopyrite at normal atmospheric pressure and $45^{\circ} \mathrm{C}$. Int. J. Miner. Process. 2017, 162, 81-91. [CrossRef]

(C) 2018 by the authors. Licensee MDPI, Basel, Switzerland. This article is an open access article distributed under the terms and conditions of the Creative Commons Attribution (CC BY) license (http://creativecommons.org/licenses/by/4.0/). 